\section{Abstract}

\title{
An elastoplastic damage model for fractured porous media
}

\author{
Jianjun. Ma ${ }^{1, a}$, Gaofeng. Zhao ${ }^{\text {b,c }}$, Nasser. Khalili ${ }^{\mathrm{c}}$ \\ ${ }^{a}$ College of Architecture and Civil Engineering, Wenzhou University, Wenzhou, Zhejiang, 325035, \\ China \\ ${ }^{b}$ State Key Laboratory of Hydraulic Engineering Simulation and Safety, School of civil Engineering, \\ Tianjin University, Tianjin, 300072, China \\ ${ }^{c}$ School of civil and Environmental Engineering, The University of New South Wales, Sydney, NSW, \\ 2052, Australia
}

An elastoplastic damage model is developed for fractured porous media. The elastic-plastic response of stress-strain is captured by a bounding surface plasticity within the critical state framework, while the damage evolution due to hydro-mechanical effects is addressed using a continuum damage model that is distinguished from the existing models by accounting for the plastic hardening parameter, stress ratio, confining pressure and strain rate. The coupling between the elastic-plastic response and damage is established by accounting for the effects of plastic volumetric strain and the damage parameter on the hardening of the bounding surface. The model is applied to different rocks subjected to isotropic and deviatoric loading in drained and undrained conditions. A good agreement is obtained between the numerical and experimental results demonstrating the ability of the model to capture the essential features of deformation in fractured porous media.

Key words: Bounding surface plasticity; Damage; Critical state; fractured porous media

\footnotetext{
${ }^{1}$ Authors to whom correspondence should be addressed.

Email address: jianjun_ma@wzu.edu.cn (Jianjun Ma)
} 


\section{$1 \quad 1$ Introduction}

2 Rocks inherently contain micro-cracks and fractures; as such, they are often referred to as

3 fractured porous media. From a microscopic point, rock deformation is associated with intact

4 response, micro-defect initiation and propagation, nucleation, reactivation of existing defects

5 and final failure. Macroscopically, this procedure is characterised as the elastic and plastic

6 deformation, including the degeneration of elastic and overall stiffness, as well as a reduction

7 in strength or load-carrying capacity (Ofoegbu and Curran, 1992).

8 Generally, there are two main classes of damage models: micromechanics-based models (or

9 localized model) and phenomenological models (macroscopic models). Although micromechanics-based damage models can describe the evolution of crack density or the growth of a single crack explicitly, conventionally the effect of such evolution is averaged across uniformly distributed representative volume elements (Yuan and Harrison, 2006). As such, these models are better able to address micro-scale problems with well-defined crack or crack system, the geometrical and mechanical properties of which are prescribed. By contrast, without considering evolution of each micro-crack, phenomenological damage models are able to describe the macroscopic response of material with minimal parameters by averaging the effects of micro-defects over the entire material (Yuan and Harrison, 2006).

In terms of macroscopic approach, four main families of constitutive models may be identified for fractured porous media: elastic, elastic damage, elastoplastic and elastoplastic damage models. In early research, most constitutive models applied in analysis were based on elasticity (HooKe's law), which would only predict the linear brittle behaviour for most rocks. Later, the elastic damage model employs continuum damage mechanics to capture the strength degradation phenomenon. It assumes a damage threshold value, beyond which the stress-strain response is not linear elastic and reconsidered as softening with a damage scalar 
1 or tensor. Yet, the ductile stress-strain relation has not been described properly by this

2 approach, as most fractured porous medias (rock and concrete) have some residual strength

3 even reaching the peak tension strength (de Borst, 2002). Therefore, elastoplastic and

4 elastoplastic damage models have been considered as the most continuously and intensively

5 investigated subjects recently. Many contributions have been made to both families of

6 models, they include among others, the bounding surface models of Guo and Wan (1998),

7 modified cap models of Sinha et al. (2010), cam-clay models developed by Shah (1997);

8 Drucker-prager model of Arslan (2007), and poroplastic damage models (Shojaei et al.,

9 2014). These models are attractive because they are simple and convenient for using. The representative of elastoplastic model combined with continuum damage concept is the work of Shao et al. (2006). Many of these models show some agreement with experimental results, but they are often based on restrictive assumptions rendering them applicable only to specific rocks or test rocks used for their calibration. For example, the cam-clay model (Shah, 1997) are only applicable to soft rocks with high porosity; the modified cap model (Dolarevic and Ibrahimbegovic, 2007) and Drucker-Prager model (Arslan, 2007) are limited to quasi-brittle rocks with low and medium porosity. Furthermore, most of these models do not fully take into account the effects of confining pressure and the plastic hardening/softening effect in damage evolution, particularly in transition from ductile to brittle behaviour.

The main objective of this paper is to develop a unified coupled elastoplastic damage model for fractured porous media suited to a wide range of confining pressures. A bounding surface plasticity model (Khalili et al., 2005) is adopted to capture the macro-response of rock under different loading conditions. Compared with the theories of conventional plasticity, bounding surface ensures smooth transition from elastic to elastic-plastic deformation and allows accumulation of plastic strains due to cycles of loading and unloading inside the conventional 
1 yield surface. Damage evolution law is established in the framework of irreversible

2 thermodynamics, taking into account the effects of plastic hardening, strain rate, stress ratio

3 as well as the confining pressure. Damage initiation criterion is based on the strain energy

4 release rate and the tensile principle stress. The damaged elastic parameters are defined using

5 the hypothesis of complementary energy equivalence (Valliappan et al., 1990). Special

6 attention is given to identifying model parameters in terms of measureable coefficients, and

7 the interaction of plastic flow and damage evolution is emphasized. Application of the model

8 is demonstrated using a host of experimental data from the literature.

\section{$9 \quad 2$ Sign Convention and Notation}

Following geomechanical sign convention, compression is taken as positive and tension as negative. Triaxial notation is applied throughout: the mean effective stress $p^{\prime}=\operatorname{Tr}\left(\sigma^{\prime} / 3\right)$, the deviatoric stress $q=\sqrt{3 J_{2}}$ and the stress ratio $\eta=q / p^{\prime}$ for which $J_{2}=(S: S) / 2$ and $\boldsymbol{S}=\boldsymbol{\sigma}^{\prime}-\operatorname{Tr}\left(\boldsymbol{\sigma}^{\prime} / 3\right)$ are the second invariant of deviatoric stress and the deviatoric stress tensor, respectively. The corresponding conjugates are the volumetric strain $\varepsilon_{v}=\operatorname{Tr}(\varepsilon)$ and the deviatoric strain $\varepsilon_{q}=\sqrt{2 / 3\left(\varepsilon^{d e v}: \varepsilon^{d e v}\right)}$ for which $\varepsilon^{d e v}=\varepsilon-\delta \operatorname{Tr}(\varepsilon) / 3$. The stress and strain pairs are written in general vector form $\sigma^{\prime}=\left[\begin{array}{ll}p^{\prime} & q\end{array}\right]^{T}$ and $\varepsilon=\left[\begin{array}{ll}\varepsilon_{v} & \varepsilon_{q}\end{array}\right]^{T}$.

\section{Conceptual Model}

The formulation presented conceptually consists of two components: an elasto-plastic model and a continuum damage model. The macro-scale elasto-plastic behaviour is described by a bounding surface plasticity, which accounts for damage effects by introducing a damage 
1 variable in the yield and plastic hardening functions. The pre-existing cracks, initiation,

2 propagation and accumulation of micro-cracks and other defects are captured using the

3 continuum damage model. The model takes into account the effects of plastic hardening,

4 strain rate, confining pressure and damage on the mechanical response in a

5 thermodynamically consistent framework.

\section{Continuum Damage Model}

\section{$7 \quad 4.1$ General Thermodynamic Framework}

8 Lemaitre and Chaboche (1978) introduced damage and its associated variables as internal

9 variables into a thermodynamics framework. Within this context, during the evolution of 10 micro-defects (initiation, growth or nucleation), a new free surface is generated and a certain 11 amount of energy is dissipated, which is assumed to consist of two parts: elastic energy $\left(\varphi_{e}\right)$

12 and plastic energy $\left(\varphi_{p}\right)$. Under isothermal conditions, the free energy $\varphi$ is taken in the form 13 of a thermodynamic potential as (Lemaitre, 1984):

$$
\varphi=\varphi_{e}\left(\varepsilon-\varepsilon^{p}, D\right)+\varphi_{p}\left(\gamma_{p}, D\right)
$$

14 or

$$
\varphi=\frac{1}{2}\left[\boldsymbol{\varepsilon}-\boldsymbol{\varepsilon}^{p}\right]^{T}\left[\boldsymbol{C}^{e}(D)\right]\left[\boldsymbol{\varepsilon}-\boldsymbol{\varepsilon}^{p}\right]+\varphi_{p}\left(\gamma_{p}, D\right)
$$

15 where $\boldsymbol{\varepsilon}$ and $\boldsymbol{\varepsilon}^{p}$ are the total and plastic strains, respectively; $D$ is the damage variable;

$16 \boldsymbol{C}^{e}(D)$ is the elastic stiffness tensor of the damaged material; $\gamma_{p}$ is the internal variable for 17 the plastic strain energy. 
1 The standard derivation of the thermodynamic potential yields state equations for stress and

2 the damage strain energy release rate (Lemaitre, 1984; Ma et al., 2016):

$$
\begin{aligned}
& \boldsymbol{\sigma}=\frac{\partial \varphi}{\partial \boldsymbol{\varepsilon}^{e}}=\left[\boldsymbol{C}^{e}(D)\right]\left[\boldsymbol{\varepsilon}-\boldsymbol{\varepsilon}^{p}\right] \\
& Y=-\frac{\partial \varphi}{\partial D}=-\frac{1}{2}\left[\boldsymbol{\varepsilon}-\boldsymbol{\varepsilon}^{p}\right]^{T}\left[\boldsymbol{C}^{e}(D)\right]^{\prime}\left[\boldsymbol{\varepsilon}-\boldsymbol{\varepsilon}^{p}\right]-\frac{\partial \varphi_{p}}{\partial D}
\end{aligned}
$$

3 where $\left[\boldsymbol{C}^{e}(D)\right]^{\prime}$ is the derivation of the elastic stiffness tensor with respect to the damage

4 variable $D$. Satisfying the second principle of thermodynamics, the damage dissipation must 5 obey (Lemaitre, 1984):

$$
Y \dot{D} \geq 0
$$

$6 \quad Y$ is also called the damage strain energy associated with damage variable. Recalling 7 Equation (3), the stress rate is calculated by (Ma et al., 2016):

$$
\dot{\boldsymbol{\sigma}}=\left[\boldsymbol{C}^{e}(D)\right]^{\prime}\left[\boldsymbol{\varepsilon}-\boldsymbol{\varepsilon}^{p}\right] \dot{D}+\left[\boldsymbol{C}^{e}(D)\right]\left[\dot{\boldsymbol{\varepsilon}}-\dot{\boldsymbol{\varepsilon}}^{p}\right]
$$

8 Note that for rocks saturated with water, hydro-mechanical effect is addressed through effect

9 stress concept, without special notification the effective stress is applied throughout this 10 paper and the incremental form of effective stress $\left(\dot{\sigma}^{\prime}\right)$ is expressed as:

$$
\dot{\sigma}^{\prime}=\dot{\sigma}-\delta \dot{u}
$$

11 where $\dot{u}$ is the incremental pore water pressure. Thus, the effective stress rate is taken as (Ma et al., 2016): 


$$
\dot{\boldsymbol{\sigma}}^{\prime}=\left[\boldsymbol{C}^{e}(D)\right]^{\prime}\left[\boldsymbol{\varepsilon}-\boldsymbol{\varepsilon}^{p}\right] \dot{D}+\left[\boldsymbol{C}^{e}(D)\right]\left[\dot{\boldsymbol{\varepsilon}}-\dot{\boldsymbol{\varepsilon}}^{p}\right]
$$

1

2 There are two main hypotheses for the behaviour of damaged materials: one is the strain

3

4

5

6

7

8

9

10

11

12

Recalling Equation (8), the elastic stress rate can take the form (Ma et al., 2016):

$$
\dot{\sigma}^{\prime}=-2(1-D) \dot{D}\left(\boldsymbol{C}^{e}\right)\left(\boldsymbol{\varepsilon}^{e}\right)+(1-D)^{2}\left(\boldsymbol{C}^{e}\right)\left(\dot{\boldsymbol{\varepsilon}}^{e}\right)
$$

\subsection{Damage Hypothesis}

equivalence (Lemaitre and Chaboche, 1975), and the other based on the complementary energy equivalence (Valliappan et al., 1990). As indicated by Valliappan et al. (1990), the adoption of complementary energy equivalence for damage modelling provides a reasonable hypothesis for all damage states, both isotropic and anisotropic. The hypothesis is stated as "the complementary energy of damage state is assumed to be equal to that of the undamaged state under effective (latent) stress loading" (Valliappan et al., 1990). Applying the hypothesis of complementary energy equivalence, the elastic stress matrix and Poisson's ratio for the damaged material can be given as (Valliappan et al., 1990):

$$
C^{e}(D)=(1-D)^{2} C^{e} \quad v(D)=v
$$

where $\boldsymbol{C}^{e}$ and $v$ are the intrinsic elastic stiffness and Poisson's ratio, respectively.

\subsection{Damage Criterion}

The damage criterion can be formed in terms of the damage strain energy release rate and the threshold of damage release rate. For isotropic damage, the damage criterion is explored in the form of a simple function as (Shao et al., 2006): 


$$
f_{d}(Y, D)=Y-Y_{d}=0
$$

1 where $Y_{d}$ is the damage strain energy release threshold for the complex mechanism of elasto-

2 plastic damage behaviour. For the sake of simplicity, Shao et al. (2006) expressed $Y_{d}$ as a

3 linear function of damage $D$. However, this is only valid for brittle materials under low to

4 medium confining pressure. Considering the effect of plastic hardening energy, the

5 hydrostatic pressure-dependent brittle/ductile behaviour of rock materials, and adopting Shao

6 et al. (2006)'s approach, we estimate the threshold of damage strain energy release rate $Y_{d}$ by

7 a kinematic function of the hydrostatic stress state $\left(p^{\prime}\right)$, the damage variable $(D)$ and the 8 plastic hardening modulus $(h)$ as:

$$
Y_{d}=Y_{d 0}+k_{Y} D \ln \left(p^{\prime}\right) \exp \left(\frac{1}{h}\right)
$$

9 where $Y_{d 0}$ is the initial threshold of damage evolution, which depends on the initial damage 10 state and stress state; and $k_{Y}>0$ is the material constant that defines the increase in the rate 11 of the damage evolution threshold.

12 For brittle materials, $Y_{C}$ is introduced as rupture criterion; i.e. if $Y=Y_{C}$, large-scale brittle 13 rupture occurs. The associated damage variable is $D_{C}$, which based on the work of Lemaitre 14 (1984) has the limits:

$$
0.2 \leq D_{c} \leq 0.8
$$


1 For fractured porous media, the critical damage value $D_{C}$ may be used to link the internal

2 crack development to macroscopic fracture beyond which brittle fracture occurs in the rock

3 sample. The damage consistency condition is written as (Shao et al., 2006):

$$
\dot{f}_{d}=\dot{Y}-\dot{Y}_{d}=0
$$

\section{$4 \quad 4.4$ Damage Evolution}

5 The damage evolution rate can be obtained conceptually by using a general damage evolution

6 law:

$$
\dot{D}=\dot{D}_{D}(D, \cdots)
$$

7 where $\dot{D}_{D}(D, \cdots)$ is the nonnegative damage increment function, which controls the damage

8 evolution rate, and can be expressed by using the loading-unloading condition according to 9 the Kuhn-Tucker relations (Shao et al., 2006):

$$
f_{d}=0, \dot{D} \geq 0, f_{d} \dot{D}=0
$$

10 With the constitutive equations, it is necessary to specify the damage evolution equation for

11 complete damage analysis. In general, two main approaches are widely applied to develop the

12 damage evolution equations: damage strain energy release rate approach and tensile principle

13 stress approach. Obviously, such two approaches should be identity to each other to describe

14 the deterioration of material: both brittle and ductile damage. Thus, damage evolution equations based on both approaches are developed in this paper, which may be of interested for some researchers. 
2 From the thermodynamic potential Equation (1), the free energy contains elastic $\left(\varphi_{e}\right)$ and

3 plastic $\left(\varphi_{p}\right)$ parts. The elastic complementary energy release rate is defined as the rate of

4 energy dissipation for the propagation of micro-cracks; it is based on the comparison between

5 the stiffness before and after the development of micro-cracks, and the strain energy release

6 rate in the framework of linear fracture mechanics (Yazdchi et al., 1996). The function of the

7 elastic complementary energy is given as:

$$
\varphi_{e}=\frac{1}{2}\left[\sigma^{\prime}\right]^{T}\left[C^{e}(D)\right]^{-1}\left[\sigma^{\prime}\right]
$$

8 The plastic function $\varphi_{p}\left(\gamma_{p}, D\right)$ represents the locked plastic energy for plastic hardening of 9 damaged material. Shao et al. (2006) applied a reduction of the plastic hardening rate to consider the influence of damage evolution on plastic flow; it is written as:

$$
\varphi_{p}\left(\gamma_{p}, D\right)=\left(1-\mu_{D} D\right) \varphi_{p}^{o}\left(\gamma_{p}\right)
$$

11 where $\varphi_{p}^{o}\left(\gamma_{p}\right)$ is defined as the plastic hardening energy for undamaged material and

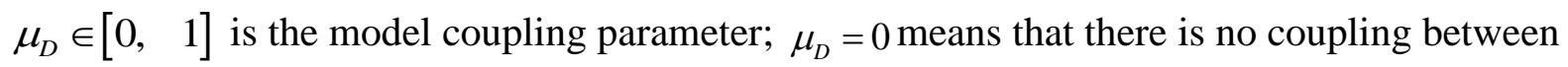
plastic flow and damage evolution. Following the work of Shao et al. (2006), we assume the confining pressure $\left(p_{c o n}^{\prime}\right)$ affects damage and grain crushing under the crushing pressure $\left(p^{*}\right.$

15 ), and the plastic energy for the undamaged material is defined by

$$
\varphi_{p}^{o}\left(\gamma_{p}\right)=M_{p}\left[p^{*} \gamma_{p}-\frac{\left(p^{*}-p_{c o n}^{\prime}\right) \gamma_{p}}{\chi+\gamma_{p}}\right]
$$


1 where $M_{p}$ is the hardening rate parameter, $\chi$ is the plastic strain parameter that accounts for

2 the strain rate effects, it can take the loading rate; the plastic strain energy variable $\gamma_{p}$ is

3 defined as the equivalent plastic deviatoric strain:

$$
\dot{\gamma}_{p}=\sqrt{\frac{2}{3}\left(\dot{\boldsymbol{\varepsilon}}^{p}-\frac{1}{3} \operatorname{tr}\left(\dot{\boldsymbol{\varepsilon}}^{p}\right) \boldsymbol{\delta}\right):\left(\dot{\boldsymbol{\varepsilon}}^{p}-\frac{1}{3} \operatorname{tr}\left(\dot{\boldsymbol{\varepsilon}}^{p}\right) \boldsymbol{\delta}\right)}
$$

$4 \quad$ The damage strain energy release rate is expanded by substituting Equations (18) and (19) 5 into (4):

$$
Y=-\frac{\partial \varphi}{\partial D}=-\frac{1}{2}[\boldsymbol{\sigma}]^{T}\left(\left[\boldsymbol{C}^{e}(D)\right]^{-1}\right)^{\prime}[\boldsymbol{\sigma}]+\mu_{D} M_{p}\left[p^{*} \gamma_{p}-\frac{\left(p^{*}-p_{c o n}^{\prime}\right) \gamma_{p}}{\chi+\gamma_{p}}\right]
$$

6 Inspired by the power law for the damage evolution of brittle materials (Yazdchi et al., 1996) 7 and the damage model for ductile fracture (Lemaitre, 1985), consistent with enough 8 experimental study of rock behaviour from the literature (Baud et al., 2000; Shah, 1997), the 9 damage strain energy release rate and strain rate $(\dot{\gamma})$ are applied to the damage evolution law 10 as

$$
\dot{D}=\left\{\begin{array}{cc}
M_{Y}(Y)^{1 / m} \dot{\gamma} & Y>Y_{d} \\
0 & Y \leq Y_{d}
\end{array}\right.
$$

11 which is different from the conventional damage evolution laws. The damage evolution rate 12 parameter $M_{Y}$ and the threshold value of damage strain energy release rate $Y_{d}$ are not constant; the parameter $m>1$ is a material constant and can be determined by experimental measurement; $\dot{\gamma}$ is introduced to ensure that there is no explicit dependency of $D$ with time (Lemaitre, 1985), for general loading conditions. It is defined as: 


$$
\dot{\gamma}=\sqrt{\frac{2}{3}(\dot{\varepsilon}: \dot{\varepsilon})}
$$

1 For rocks subject to deviatoric stress, the interaction of local tensile stress and shear stress

2 acting on the tips and surfaces of micro-cracks may induce micro-crack propagation (Guo 3 and Wan, 1998). Because the hydrostatic stress may induce closure of micro-cracks, the 4 stress ratio $\left(\eta=q / p^{\prime}\right)$ is used to address the interaction between the deviatoric and

5 hydrostatic stresses. Taking into account the confining pressure $\left(p_{c o n}^{\prime}\right.$ or $\left.\sigma_{3}^{\prime}\right)$, the slope of the

6 critical state line $\left(M_{c s}\right)$ and the stress ratio $\left(\eta=q / p^{\prime}\right)$, the damage evolution rate parameter

$7 \quad M_{Y}$ is expressed as:

$$
M_{Y}=m_{Y}|\ln \omega|\left|\ln \left(\frac{M_{c s}+\eta}{2 M_{c s}}\right)\right|
$$

8 where $m_{Y}>0$ is a material constant and may be determined by fitting the experimental

9 results. The effects of the confining pressure on material behaviour can be addressed by a 10 ratio parameter $\omega=p_{c o}^{\prime} /\left(p_{c o n}^{\prime}+1\right)$, where $p_{c o}^{\prime}$ is the maximum hydrostatic compressive 11 pressure. The logic for adding confining pressure to damage evolution rate is that rock-like 12 materials undergo cracking in tension and crushing in compression (Zhou et al., 2013). The maximum hydrostatic compressive pressure $\left(p_{c o}^{\prime}\right)$ serves as an important parameter in the transition between different failure modes (Cuss et al., 2003).

16 Kachanov (1980) proposed a damage kinematic equation based on the function of the tensile 17 principle stress for crack and damage evolution in ductile damaged materials. Yazdchi et al. 
1 (1996) adopted this damage evolution law to investigate the damage growth in brittle

2 materials. Both of these studies obtained good estimates for the behaviour of damaged

3 materials (brittle and ductile). After studying the mechanical behaviour of sandstones in the

4 literature (Baud et al., 2000), experimental data show that the damage evolution of porous

5 media mainly depends on factors such as the confining pressure, strain rate, porosity and

6 stress ratio $\left(\eta=q / p^{\prime}\right)$. Based the work of Yazdchi et al. (1996) and Lemaitre (1985), a more

7 rigorous treatment of the damage evolution law is proposed herein. In fracture mechanics,

8 fracture occurs when the specific principle tensile stress exceeds the tensile strength in the

9 stress space. When rock materials are subjected to both hydrostatic and deviatoric stress, under the hypothesis of isotropic damage, the concept of equivalent stress $\left(\sigma_{e q}=\sqrt{3 J_{2}}\right)$ is applied. The damage evolution law based on the tensile principle stress is therefore given as:

$$
\dot{D}=\left\{\begin{array}{cc}
M_{\sigma}\left(\sigma_{e q}\right)^{1 / n} \dot{\gamma} & \sigma_{e q}>\sigma_{e q d} \\
0 & \sigma_{e q} \leq \sigma_{e q d}
\end{array}\right.
$$

where $n>1$ is the material constant and can be obtained by experimental measurement, and $M_{\sigma}$ is the damage evolution rate parameter. Similar to the kinematic function of $M_{Y}, M_{\sigma}$ depends on the stress state (confining pressure and stress ratio), and the formula for $M_{\sigma}$ is

$$
M_{\sigma}=m_{\sigma}|\ln \omega|\left|\ln \left(\frac{\eta+M_{c s}}{2 M_{c s}}\right)\right|
$$

where $m_{\sigma}>0$ is a material constant. $\sigma_{e q d}$ is the threshold of damage equivalent stress. As mentioned previously, the hydrostatic stress suppresses the development of micro-cracks, the damage variable represents the degradation of the material stiffness, and the plastic hardening energy indicates the trend of hardening or softening in the stress space. Taking into account 
1 the hydrostatic stress $\left(p^{\prime}\right)$, the damage state $(D)$ and the plastic hardening $(h)$ effect, the

2 function for $\sigma_{e q d}$ is given as:

$$
\sigma_{e q d}=\sigma_{e q d 0}+\frac{k_{\sigma} p^{\prime} \exp (1 / h)}{(1-D)}
$$

3 where $\sigma_{\text {eqd }}$ is the initial threshold of the damage equivalent stress and only depends on the

$4 \quad$ stress and damage states; $k_{\sigma}>0$ is a material constant and controls the increase in rate for the

5 damage equivalent stress threshold.

6 It is noted that grain crushing may occur in rock materials when the ultimate high pressure (

$7 \quad p_{c o}^{\prime}$ ) is applied. During grain crushing, the values of $M_{Y}$, obtained from Equation (24), and

$8 M_{\sigma}$, calculated from Equation (26), become infinitely small (close to zero), which means

9 that plasticity dominates the deformation, and there is little damage evolution in the ductile

10 regime. It is interesting to note that, the threshold values of damage strain energy release rate

11 in Equation (12) and damage equivalent stress in Equation (27) take into account the effective

12 hydrostatic stress. The logic is that: when the pore water pressure rises, the closed fractures or cracks may reopen, which reduces the threshold value of damage and paves the way for tension cracking or hydraulic cracking, accordingly. In contrast, when the pore water pressure decreases, the open cracks and fractures may be inhibited as a result of the increase in the effective mean stress; consequently, the threshold value of damage increases and further damage evolution inhibited demanding higher pressures. 


\section{Plasticity Model}

\subsection{The Critical State}

3 The critical state is defined as the state of porous rock that approaches a large shear

4 deformation at constant shear stress and constant volume. The critical state line (CSL)

5 separates the brittle and ductile deformation domains in the $p^{\prime}-q$ plane and can be seen as

6 the state of the brittle-ductile transition, which is in agreement with the work of Shah (1997)

7 and Cuss et al (2003). The slope of CSL $\left(M_{c s}\right)$ as a function of the effective frictional angle at

8 critical state $\left(\phi_{c s}^{\prime}\right)$ is defined as:

$$
M_{c s}=\frac{6 \sin \phi_{c s}^{\prime}}{3 A-\sin \phi_{c s}^{\prime}}
$$

9 where, $A=+1$ represents the compressive loading $(\bar{q}>0)$ and $A=-1$ for extension 10 loading $(\bar{q}<0)$.

11 Based on the substantial body of experimental data presented in the literature (Baud et al., 2000; Cuss et al., 2003), it can be stated that the damage evolution would not change the slope of critical state line (CSL) in the $q-p^{\prime}$ plane. However, in the $v-\ln p^{\prime}$ plane, the isotropic compression line ( $\left.\mathrm{ICL}_{\mathrm{D}}\right)$ and unloading-reloading line $\left(\mathrm{URL}_{\mathrm{D}}\right)$ become steeper with increasing damage, compared with the straight lines for undamaged material. This change in the slope of the $\mathrm{ICL}_{\mathrm{D}}$ is due to the shift of ICL with damage. Experimental data from Zhang et al. (1990a) and Zhang et al. (1990b) is plotted in Figure 1. These figures demonstrate the effect of damage on the slope and the position of the critical state, unloading-reloading and the isotropic compression lines. Plots indicate that the critical state and isotropic compression 
1 lines shift downwards with steeper slopes when damage is increased. Meanwhile, the slope of

2 unloading-reloading line shifts upwards to be steeper.

3

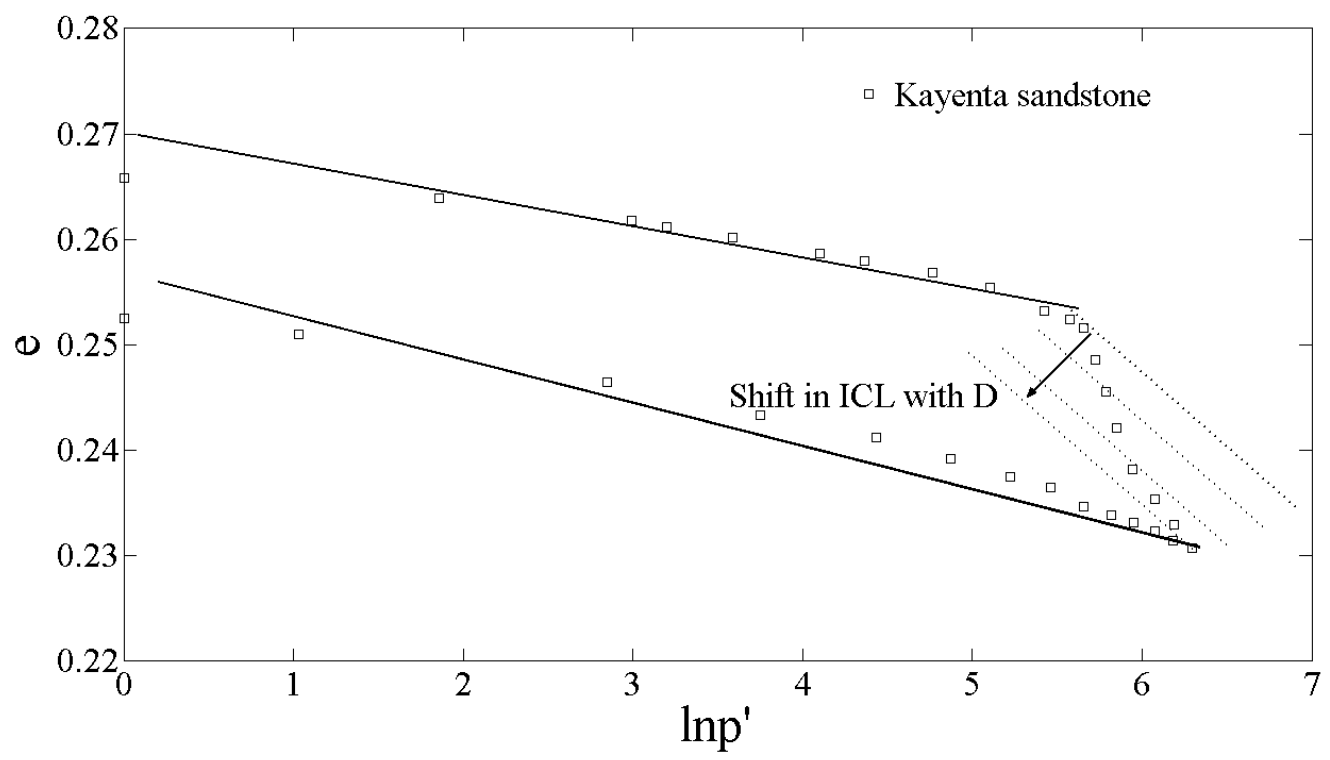

Figure 1 (a)

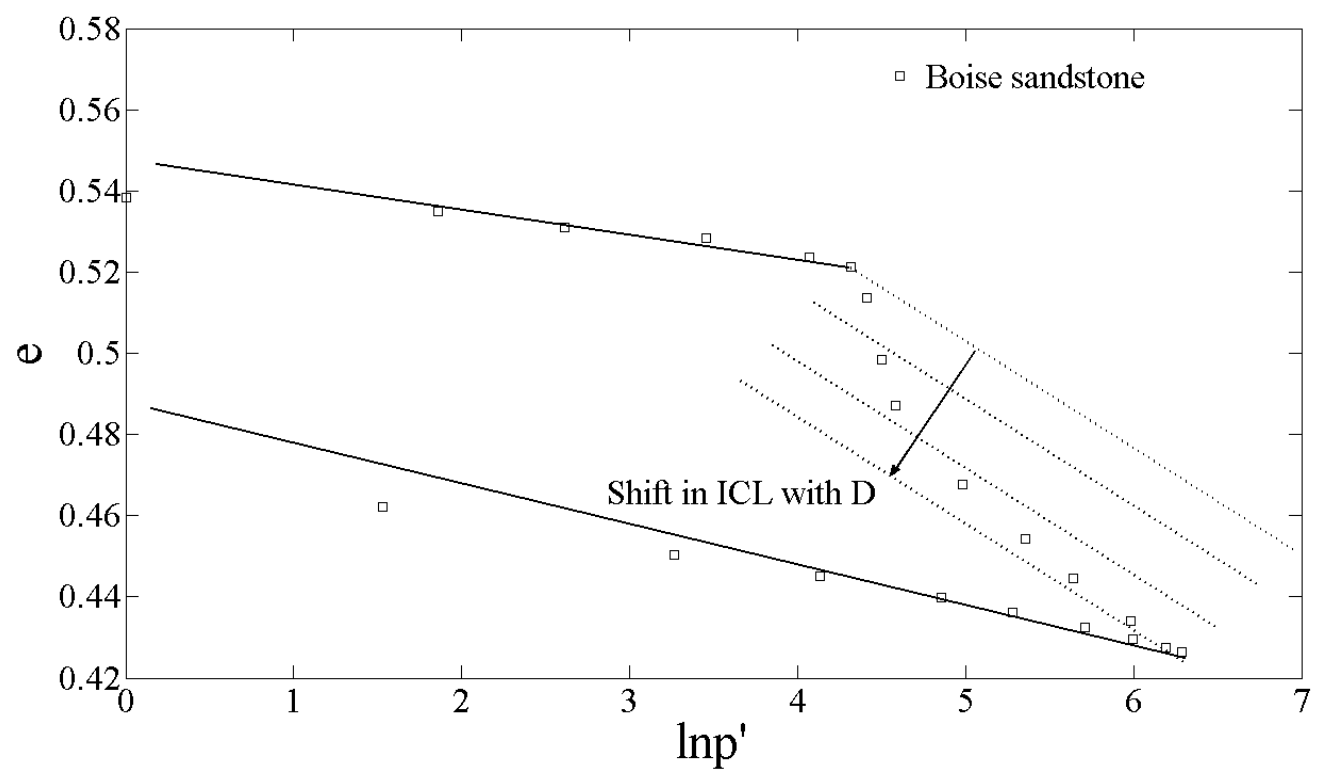

6

Figure 1 (b) 
1

4

5

6 Following the empirical approach, the critical state line $\left(\mathrm{CSL}_{\mathrm{D}}\right)$ is assumed to be parallel to

7 the ICL $L_{D}$ in the $v-\ln p^{\prime}$ plane. The damage induced changes in the slope of URL and values

8 of the specific volume at the intersections of the ICL and CSL at $p^{\prime}=1 \mathrm{KPa}$ (or $1 \mathrm{MPa}$ ) are $9 \quad$ expressed as (shown in Figure 2):

$$
\begin{aligned}
& \kappa_{D}=\kappa(D) \\
& N_{D}=N(D) \\
& \Gamma_{D}=\Gamma(D)
\end{aligned}
$$

Figure $1(\mathbf{c})$ 


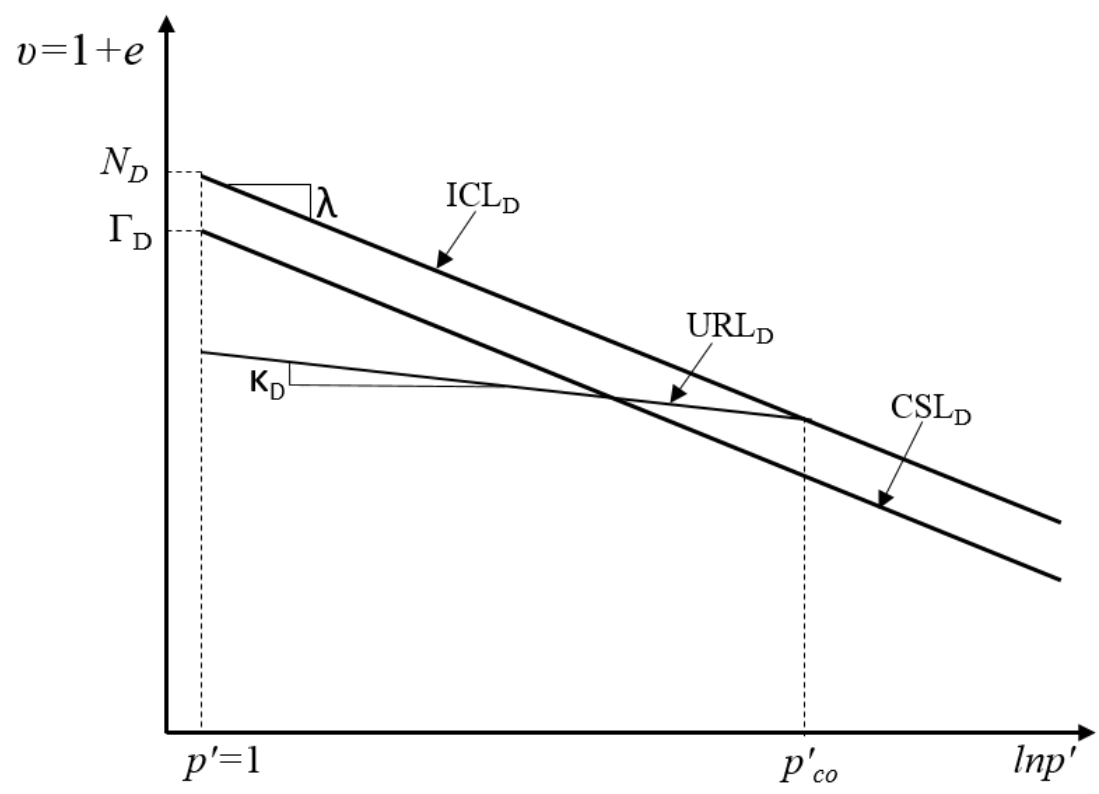

2 Figure 2: Schematic illustrations for the critical state line $\left(\mathrm{CSL}_{\mathbf{D}}\right)$, the isotropic compression line $\left(I C L_{D}\right)$, and the unloading-reloading line $\left(\mathrm{URL}_{\mathbf{D}}\right)$ in the $v-\ln p^{\prime}$ plane.

4 The corresponding damaged bulk modulus is expressed by (Ma et al., 2016):

$$
K_{b u l k}^{e}(D)=\frac{v p^{\prime}}{\kappa_{D}}
$$

5 The damaged bulk modulus takes the current hydrostatic pressure and damage variable into

6 account. The physical implication of this is that it captures the degradation of the elastic

7 stiffness induced by the development of micro-cracks, including the reopening of existing

8 cracks and the increase in the elastic modulus enhanced by the closure of cracks under

9 compaction. Specifically, when the damage increases (e.g., a new fracture is generated), the 10 slope of the unloading-reloading line $\kappa_{D}$ increases, and thus, the bulk modulus decreases.

11 Based on the damage hypothesis (Equation (7)), the damage elastic bulk modulus is related to 12 the bulk modulus for undamaged material as follows: 


$$
K_{b u l k}^{e}(D)=(1-D)^{2} K_{b u l k}^{e}=(1-D)^{2} \frac{v p^{\prime t}}{\kappa}
$$

1 Therefore, combining the concept of latent stress $\left(p^{\prime t}\right)$ yields:

$$
\begin{aligned}
& \kappa_{D}=\frac{\kappa}{1-D} \\
& G^{e}(D)=\frac{3(1-2 v)}{2(1+v)} K_{b u l k}^{e}(D)
\end{aligned}
$$

2 which means that, during the onset of damage, the unloading-reloading line for damaged

3 material $\left(\mathrm{URL}_{\mathrm{D}}\right)$ becomes much steeper compared to the URL for undamaged material in the

$4 \quad v-\ln p^{\prime}$ plane (Figure 2). Therefore, compared with undamaged material, damaged material 5 undergoes more volumetric change under the same unloading stress, which reflects the 6 degradation of the material stiffness.

\section{$7 \quad 5.2$ Elastic-Plastic Behaviour}

8 To capture the deformation behaviour of fractured rocks, we first assume that the strain 9 increment consists of elastic and plastic increments as: $\dot{\boldsymbol{\varepsilon}}=\dot{\boldsymbol{\varepsilon}}^{e}+\dot{\boldsymbol{\varepsilon}}^{p}$. The elastic incremental 10 strain relates to the incremental stress in Equation (8) and is rewritten by introducing the 11 damaged elastic stiffness and damage variable:

$$
\dot{\boldsymbol{\sigma}}^{\prime}=-\frac{2 \dot{D}}{1-D}\left[\boldsymbol{C}^{e}(D)\right]^{\prime} \boldsymbol{\varepsilon}^{e}+\left[\boldsymbol{C}^{e}(D)\right]\left(\dot{\boldsymbol{\varepsilon}}-\dot{\boldsymbol{\varepsilon}}^{p}\right)
$$

12 where $\boldsymbol{C}^{e}$ is the intrinsic elastic modulus matrix for undamaged material. The damaged elastic modulus is expressed as: 


$$
\boldsymbol{C}^{e}(D)=\left[\begin{array}{cc}
K_{b u l k}^{e}(D) & 0 \\
0 & 3 G^{e}(D)
\end{array}\right]
$$

1 For plasticity, the corresponding incremental plastic stress-strain relationship is given by

2 (Khalili et al., 2005):

$$
\dot{\boldsymbol{\varepsilon}}^{p}=\frac{1}{h} \boldsymbol{m} \boldsymbol{n}^{T} \dot{\boldsymbol{\sigma}}^{\prime}
$$

3 where $\boldsymbol{n}=\left[\begin{array}{ll}n_{p} & n_{q}\end{array}\right]^{T}$ is the unit vector normal to the loading surface at the current stress state

$4 \quad \boldsymbol{\sigma}^{\prime} ; \boldsymbol{m}=\left[\begin{array}{ll}m_{p} & m_{q}\end{array}\right]^{T}$ is the unit direction of plastic flow at $\boldsymbol{\sigma}^{\prime}$; and $\boldsymbol{h}$ is the hardening 5 modulus. The increments of stress-strain are then rearranged as:

$$
\dot{\boldsymbol{\sigma}}^{\prime}=\left(\boldsymbol{C}^{e}(D)-\frac{\left[\boldsymbol{C}^{e}(D)\right] \boldsymbol{m} \boldsymbol{n}^{T}\left[\boldsymbol{C}^{e}(D)\right]}{h+\boldsymbol{n}^{T}\left[\boldsymbol{C}^{e}(D)\right] \boldsymbol{m}}\right)\left(\dot{\boldsymbol{\varepsilon}}-\frac{2 \dot{D}}{1-D} \boldsymbol{\varepsilon}^{e}\right)
$$

\section{$6 \quad 5.3$ Bounding Surface}

7 The plastic deformation is captured using the theory of bounding surface plasticity. In this

8 approach, plastic deformation occurs when the stress state lies on or within the bounding 9 surface. This is achieved by defining the hardening modulus $h$ as a decreasing function of the 10 distance between the stress point, $\boldsymbol{\sigma}^{\prime}$, and an "image point" on the bounding surface. The 11 image point is selected using a mapping rule such that the normals to the loading surface at $\boldsymbol{\sigma}^{\prime}$, and to the bounding surface at the image point, $\overline{\boldsymbol{\sigma}}$, are the same.

13 The shape of the bounding surface is formulated by fitting the yield points in the $q-p^{\prime}$ plane

14 for different rock materials, the expression proposed by Khalili et al. (2005) is adopted: 


$$
F\left(\bar{p}^{\prime}, \bar{q}, \bar{p}_{c}^{\prime}\right)=\bar{q}-M_{c s} \bar{p}^{\prime}\left(\frac{\ln \left(\bar{p}_{c}^{\prime} / \bar{p}^{\prime}\right)}{\ln R}\right)^{(1 / N)}=0
$$

1 where the superposed bar represents the image stress point on the bounding surface, $\bar{p}_{c}^{\prime}$

2 controls the size of the bounding surface and is a function of the damage variable $D$ and the

3 plastic volumetric strain $\varepsilon_{v}^{p} . N$ controls the shape of the bounding surface, and $R$ is the

4 ratio defined in Figure 3. For different rock materials, the fitted surface function can be 5 adjusted the parameters $N, R$ and $M_{c s}$.

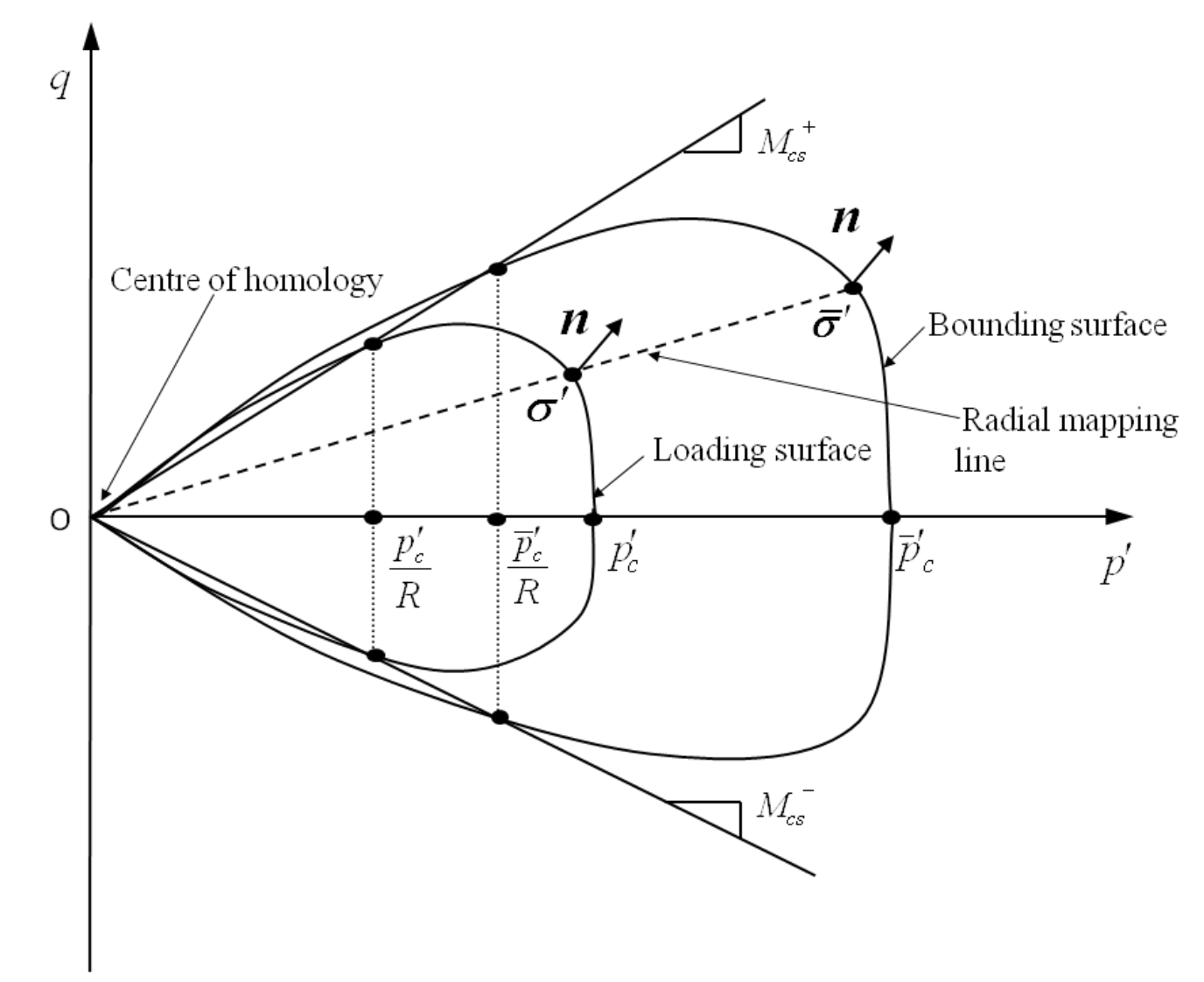


2 For monotonic loading, the loading and bounding surfaces are assumed to be of the same

3 shape and homologous about the origin in the $q-p^{\prime}$ plane. In this work, the domain of the

4 region of "true" elasticity is assumed to be of nil dimension, thus the current stress state is

5 always located on the loading surface, which is given by (Khalili et al., 2005):

$$
f\left(p^{\prime}, q, p_{c}^{\prime}\right)=q-M_{c s} p^{\prime}\left(\frac{\ln \left(p_{c}^{\prime} / p^{\prime}\right)}{\ln R}\right)^{(1 / N)}=0
$$

6 The unit normal vector at the image point defining the direction of loading is expressed by a 7 general equation:

$$
\boldsymbol{n}=\frac{\partial f / \partial \boldsymbol{\sigma}^{\prime}}{\left\|\partial f / \partial \boldsymbol{\sigma}^{\prime}\right\|}=\frac{\partial F / \partial \overline{\boldsymbol{\sigma}}^{\prime}}{\left\|\partial F / \partial \overline{\boldsymbol{\sigma}}^{\prime}\right\|}
$$

8 where, the components of $\boldsymbol{n}=\left[\begin{array}{ll}n_{p} & n_{q}\end{array}\right]^{T}$ at $\boldsymbol{\sigma}^{\prime}$ are defined by a general form (Khalili et al., 9 2005):

$$
\begin{aligned}
& n_{p}=\frac{-\bar{q} / \bar{p}^{\prime}\left[1-1 /\left(N \ln \left(\bar{p}_{c}^{\prime} / \bar{p}^{\prime}\right)\right)\right]}{\sqrt[+]{\left\{-\bar{q} / \bar{p}^{\prime}\left[1-1 /\left(N \ln \left(\bar{p}_{c}^{\prime} / \bar{p}^{\prime}\right)\right)\right]\right\}^{2}+1}} \\
& n_{q}=\frac{1}{\sqrt[+]{\left\{-\bar{q} / \bar{p}^{\prime}\left[1-1 /\left(N \ln \left(\bar{p}_{c}^{\prime} / \bar{p}^{\prime}\right)\right)\right]\right\}^{2}+1}}
\end{aligned}
$$

\subsection{Plastic Potential}

11 The plastic flow is quantified through invoking existence of a plastic potential $(g=0)$, defined as a function of the stress state and the dilatancy factor $(d)$. The dilatancy factor is 
1 positive for the opening or generation of new micro-cracks and is negative for the closure of

2 existing cracks. Since isotropic damage evolution is adopted in this research, the damage

3 variable does not affect the direction of the plastic strain. Extending Rowe's dilatancy

4 relationship, the plastic potential in $q \sim p^{\prime}$ plane is expressed as (Khalili et al., 2005):

$$
g\left(p^{\prime}, q, p_{o}\right)=q+M_{c s} p^{\prime} \ln \left(\frac{p^{\prime}}{p_{o}^{\prime}}\right)
$$

5 where $p_{o}^{\prime}$ is a dummy variable controlling the size of plastic potential. The components of

$6 \boldsymbol{m}=\left[\begin{array}{ll}m_{p} & m_{q}\end{array}\right]^{T}$ at $\boldsymbol{\sigma}^{\prime}$ are defined in a general form (Khalili et al., 2005):

$$
\begin{aligned}
& m_{p}=\frac{\partial g / \partial p^{\prime}}{\left\|\partial g / \partial \boldsymbol{\sigma}^{\prime}\right\|}=\frac{d}{\sqrt[+]{1+d^{2}}} \\
& m_{q}=\frac{\partial g / \partial q}{\left\|\partial g / \partial \boldsymbol{\sigma}^{\prime}\right\|}=\frac{1}{\sqrt[+]{1+d^{2}}}
\end{aligned}
$$

$7 \quad$ in which $d=\dot{\varepsilon}_{v}^{p} / \dot{\varepsilon}_{q}^{p}$ is the plastic dilatancy.

$8 \quad 5.6$ Plastic Damage Hardening

9 The hardening rule for the coupled plasticity damage is established considering the variation

10 of isotropic compression line with damage for an arbitrary loading path BC, as shown in 11 Figure 4. 


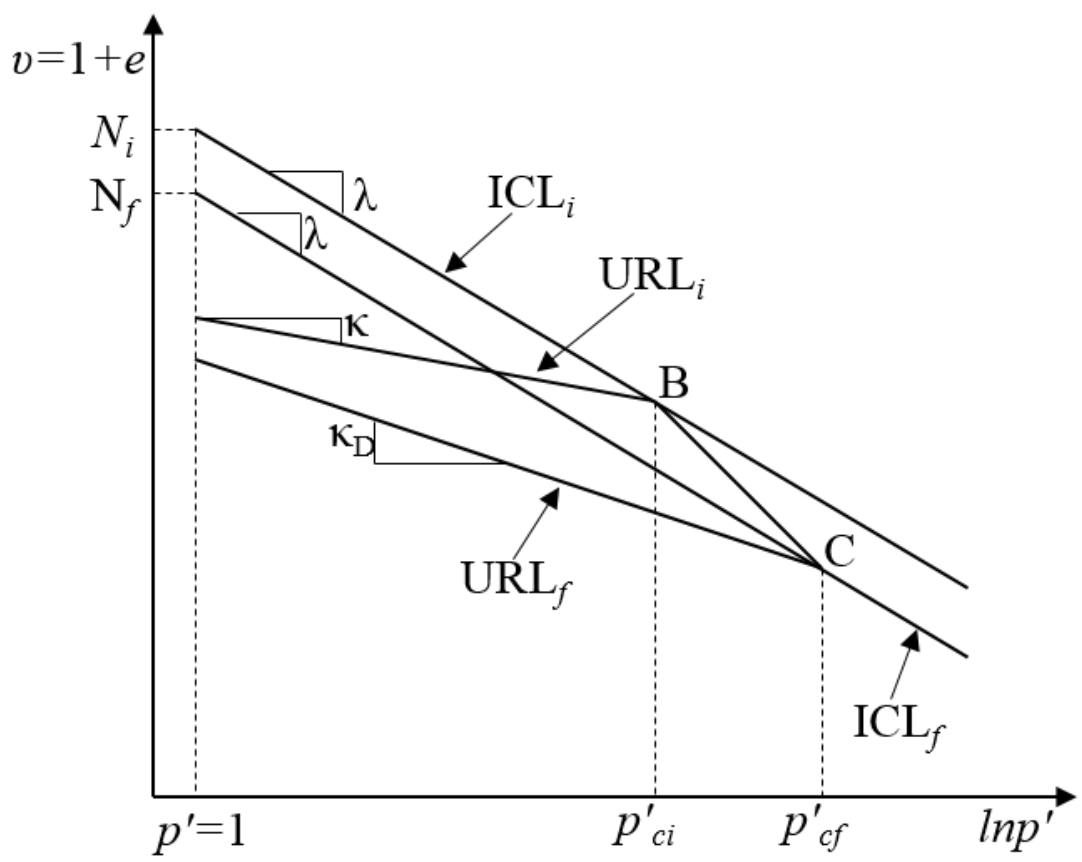

2 Figure 4: Schematic illustrations for the isotropic compression line $\left(\mathrm{ICL}_{i}, \mathrm{ICL}_{f}\right)$ and unloading3 reloading line $\left(\mathrm{URL}_{i}, \mathrm{URL}_{f}\right)$ in the $v-\ln p^{\prime}$ plane. The subscript symbol $i$ and $f$ represents the 4 initial and final damage states, respectively.

5 From point $\mathrm{B}$ to $\mathrm{C}$, the total volumetric change is:

$$
-\Delta v_{B C}=v_{B}-v_{C}=\left[N_{i}-\lambda \ln \left(p_{c i}^{\prime}\right)\right]-\left[N_{f}-\lambda \ln \left(p_{c f}^{\prime}\right)\right]
$$

6 and the elastic volumetric change is:

$$
-\Delta v^{e}=\kappa_{D} \ln \left(p_{c f}^{\prime} / p_{c i}^{\prime}\right)
$$

7 Thus, the plastic specific volume change is calculated by:

$$
-\Delta v^{p}=-\Delta v_{B C}+\Delta v^{e}=\left[N_{i}-\lambda \ln \left(p_{c i}^{\prime}\right)\right]-\left[N_{f}-\lambda \ln \left(p_{c f}^{\prime}\right)\right]-\kappa_{D} \ln \left(\frac{p_{c f}^{\prime}}{p_{c i}^{\prime}}\right)
$$


1 Rearranging Equation (48):

$$
\ln \left(p_{c f}^{\prime}\right)=\frac{\left[N_{f}-N_{i}\right]}{\lambda-\kappa_{D}}+\ln \left(p_{c i}^{\prime}\right)+\frac{-\Delta v^{p}}{\lambda-\kappa_{D}}
$$

2 and assuming the specific volume at the initial damage state (point B) is $v_{i}$, the plastic strain

3 is written as:

$$
\Delta \varepsilon_{p}^{p}=-\Delta v^{p} / v_{i}
$$

4 Since the compressive pressures $p_{c i}^{\prime}$ and $p_{c f}^{\prime}$ are corresponding to the hardening parameters at

5 the initial and final states of damaged material, substituting $\vec{p}_{c i}^{\prime}=p_{c i}^{\prime}, \vec{p}_{c f}^{\prime}=p_{c f}^{\prime}$ and equation

6 (50) into equation (49), and rearranging it, gives the coupling effects of plastic volumetric 7 strain and damage on hardening:

$$
\bar{p}_{c f}^{\prime}=\bar{p}_{c i}^{\prime} \exp \left(\frac{N_{f}-N_{i}}{\lambda-\kappa_{D}}\right) \exp \left(\frac{v_{i} \Delta \varepsilon_{p}^{p}}{\lambda-\kappa_{D}}\right)
$$

8 Notice that Equation (51) is derived from arbitrary damage states and isotropic compression

9 line. Hence, it can be applied to capture hardening at any damage state. Rearranging (51) 10 yields:

$$
\bar{p}_{c f}^{\prime}=\bar{p}_{c i}^{\prime} \hat{\gamma}(D) \exp \left(\frac{v_{i} \Delta \varepsilon_{p}^{p}}{\lambda-\kappa_{D}}\right)
$$

11 in which, $\hat{\gamma}(D)$ is the coupling effects of damage on hardening, written as: 


$$
\hat{\gamma}(D)=\exp \left(\frac{N_{f}-N_{i}}{\lambda-\kappa_{D}}\right)
$$

1 Following the usual approach in the bounding surface plasticity, the hardening modulus is

2 split into two components (Khalili et al., 2005):

$$
h=h_{b}+h_{f}
$$

3 where $h_{b}$ is the plastic modulus at $\overline{\boldsymbol{\sigma}}^{\prime}$ on the bounding surface and $h_{f}$ is the arbitrary

4 modulus. Considering the plastic consistency condition at the bounding surface, and 5 assuming that isotropic hardening of the bounding surface is associated with isotropic

6 damage evolution and plastic compressive volumetric strain, $h_{b}$ is taken as:

$$
h_{b}=-\frac{\partial F}{\partial \bar{p}_{c}^{\prime}}\left(\frac{\partial \bar{p}_{c}^{\prime}}{\partial \varepsilon_{p}^{p}}+\frac{\partial \bar{p}_{c}^{\prime}}{\partial D} \frac{\dot{D}}{\dot{\varepsilon}_{p}^{p}}\right) \frac{m_{p}}{\left\|\partial F / \partial \overline{\boldsymbol{\sigma}}^{\prime}\right\|}
$$

7 The arbitrary modulus $h_{f}$ is determined based on the distance between the image stress and

8 the current stress. Inspired by the formulation of Khalili et al. (2005), extended to take into 9 account damage in addition to the plastic volumetric strain effects, $h_{f}$ is defined as:

$$
h_{f}=A\left(\frac{\partial \bar{p}_{c}^{\prime}}{\partial \dot{\varepsilon}_{p}^{p}}+\frac{\partial \bar{p}_{c}^{\prime}}{\partial D} \frac{\dot{D}}{\dot{\varepsilon}_{p}^{p}}\right) \frac{p^{\prime}}{\bar{p}_{c}^{\prime}}\left(\frac{\bar{p}_{c}^{\prime}}{p_{c}^{\prime}}-1\right) k_{m}\left(\eta_{p}-\eta\right)
$$

10 where $\vec{p}_{c}^{\prime}$ and $p_{c}^{\prime}$ control the sizes of the bounding surface and the loading surface, 11 respectively; $\eta_{p}$ is the slope of the peak strength line in the $q-p^{\prime}$ plane; and $k_{m}$ is the 12 material parameter, which is expressed as $\eta_{p}=(1-k \xi) M_{c s}$, with $k$ being a material parameter and $\xi$ a dimensionless state parameter. $\xi$ is linked to certain features of the proposed model 
1 and defined as the vertical distance between the current state $(v)$ and the critical state $\left(v_{c s}\right)$

2 line in the $v-\ln p^{\prime}$ plane: $\xi=v-v_{c s}$, which is positive on the loose side and negative on the

3 dense side of the critical state line. It is noted that, $h_{f}$ is zero at the bounding surface and is

4 infinite at the stress reversal point (Khalili et al., 2005).

\section{Parameters Identification}

6 The proposed damage model consist of 11 parameters: $\mu_{D}, M_{p}, \chi, m, n, k_{\sigma}, k_{Y}, m_{\sigma}, m_{Y}$,

$7 \sigma_{e q d 0}$ and $Y_{d 0} \cdot \mu_{D}$ is the coupling term between damage and plasticity; for fully coupled

8 plastic-damage model $\mu_{D}=1$ and for uncoupled analysis it is equal to zero. The plastic strain

9 energy parameters for undamaged material are the hardening rate parameter $M_{p}$ and the

10 plastic strain parameter $\chi$. Inspired by Shao et al. (2006), $M_{p}$ and $\chi$ are determined through

11 the plastic hardening function (Equation (51)) where the stress state changes: two unknowns (

$12 M_{p}$ and $\chi$ ) can be solved by calculating the plastic hardening rates under triaxial tests. $m$ and $n$ are damage evolution rate exponents, they can be calibrated by fitting the damage variable ( $D$ )-damage driving force ( $Y$ and $\sigma_{e q}$ ) curves in three-point bending test or uniaxial tension test. $\sigma_{e q d 0}, Y_{d 0}, k_{\sigma}, k_{Y}, m_{\sigma}$ and $m_{Y}$ are constants for a specific material. $\sigma_{e q d 0}$ and $Y_{d 0}$ are the initial thresholds of the damage evolution and can be determined by onset point of variation of elastic properties in unloading path, with the influence of confining pressure being taken into account in this study. $k_{\sigma}$ and $k_{Y}$ control the increase rate for the damage evolution threshold values, once the initial thresholds of the damage evolution ( $\sigma_{\text {eqd } 0}$ and $Y_{d 0}$ ) are available, $k_{\sigma}$ and $k_{Y}$ are determined through the damage criteria (Equation (15)) 
1 at an arbitrary damaged state. $m_{\sigma}$ and $m_{Y}$ determine the damage evolution rate, they can be

2 estimated by studying the slope of unloading-reloading line of rocks under different confining

3 pressures. The variation of elastic modulus would indicate the development of damage ( $D$ ),

4 with data in stress or strain, $m_{\sigma}$ and $m_{Y}$ can be obtained.

5 Constitutive parameters for the elasto-plastic model are: $\kappa$ and $v$ to describe the elastic

6 behaviour; $\lambda, M_{c s}$ and $\Gamma$ to define the critical state line; $R$ and $N$ to determine the shape of

7 the bounding surface; $k$ to define the peak strength line; $k_{m}$ to calibrate the hardening

8 modulus. The elastic parameters $\kappa$ and $\nu$ with the critical state parameters $\lambda, M_{c s}$ and $\Gamma$ can be

9 determined from conventional triaxial tests. $\kappa$ is the slope of unloading-reloading line (URL) in $v-\ln p^{\prime}$ plane, $v$ is the Poisson's ratio; $\lambda$ is the gradient of the critical state line (CSL), $M_{c s}$ is the slope of the critical state line on $q-p^{\prime}$ plane, $\Gamma$ is the reference specific volume at the critical state at a unit confining pressure. $R$ and $N$ are the model parameters that define the shape of the bounding surface, they can be calibrated by studying the data of the failure surface of the rock under high pressure. $k$ is determined through the slope of $\eta_{p} / M_{c s}$ versus $\xi$. The value of $k_{m}$ can be obtained from the initial slope of drained deviatoric loading and unloading response in the $q-\varepsilon_{q}$ plane (Khalili et al., 2005).

\section{Model Performance}

Performance of the proposed model to simulate response of rocks subject to different confining pressures and varying stress paths is demonstrated using an extensive array of experimental data from the literature. The results of model prediction and experimental data are shown in Figures 5-12. In all cases, model simulations are represented by continuous lines and experimental responses by discrete symbols. 
2 Zhang et al. (1990a) conducted hydrostatic tests on Berea sandstone under constant pore 3 water pressures of $10 \mathrm{MPa}$ and $50 \mathrm{MPa}$. The physical properties of Berea sandstone are: 4 porosity $=21 \%$, average radius of grain size $=0.13 \mathrm{~mm}$; consisting of: $75 \%$ quartz, $10 \%$ 5 feldspar, 5\% calcite and 10\% clay. The cylindrical rock samples (diameter ranges from 18.4 6 to $25.4 \mathrm{~mm}$ and length falls between 18.4 and $38.1 \mathrm{~mm}$ ), were tested in conventional triaxial 7 apparatus with two separate hydraulic systems which can generate confining and pore 8 pressures. Material parameters: $e_{0}=0.226$ for the initial porosity, $v=0.25, \lambda=0.21$, $9 \kappa=0.0145, \bar{p}_{c}^{\prime}=380 \mathrm{MPa}$ and $M_{c s}=1.45$ used in the model were obtained from isotropic and diviatoric compression tests reported by (Wong et al., 1997). The material 11 constants for defining the bounding surface: $N=1.75, R=2.35, k_{m}=1$ and $k=35$ were 12 obtained from yield points in the $q-p^{\prime}$ plane for Berea sandstone. The damage model was calibrated using: $m=10, k_{Y}=0.005, m_{Y}=25$ and $Y_{d 0}=0.001$.

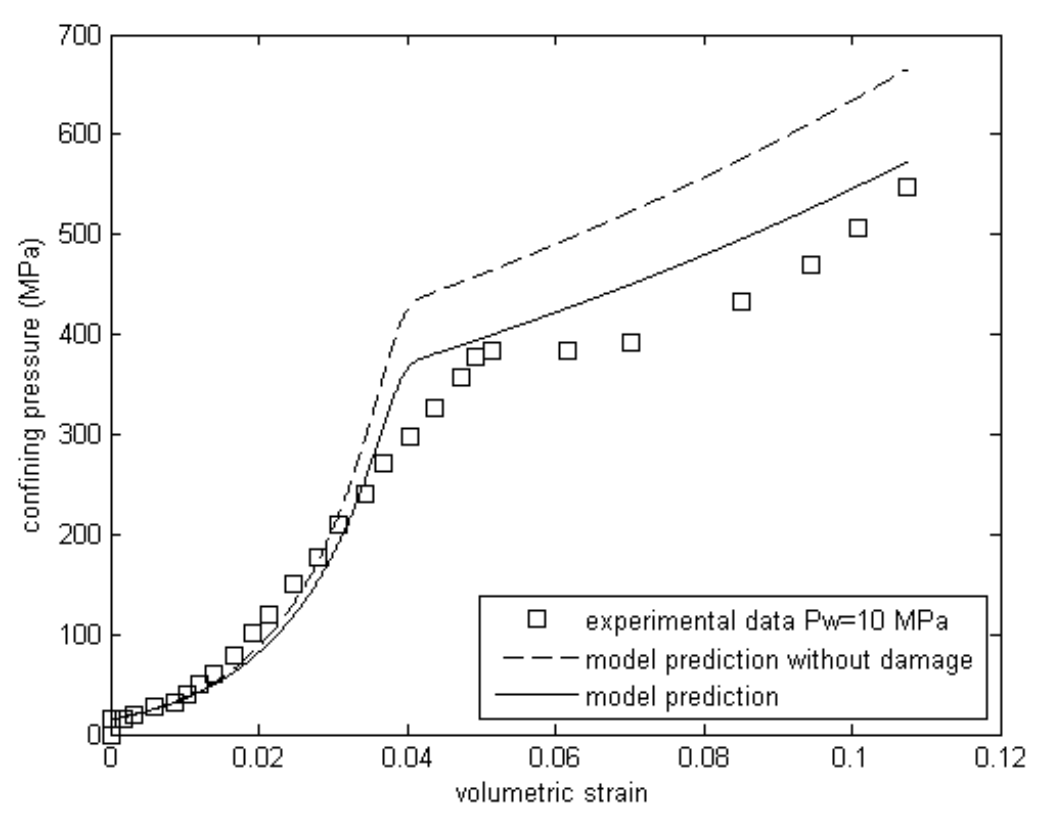

Figure 5 (a) 


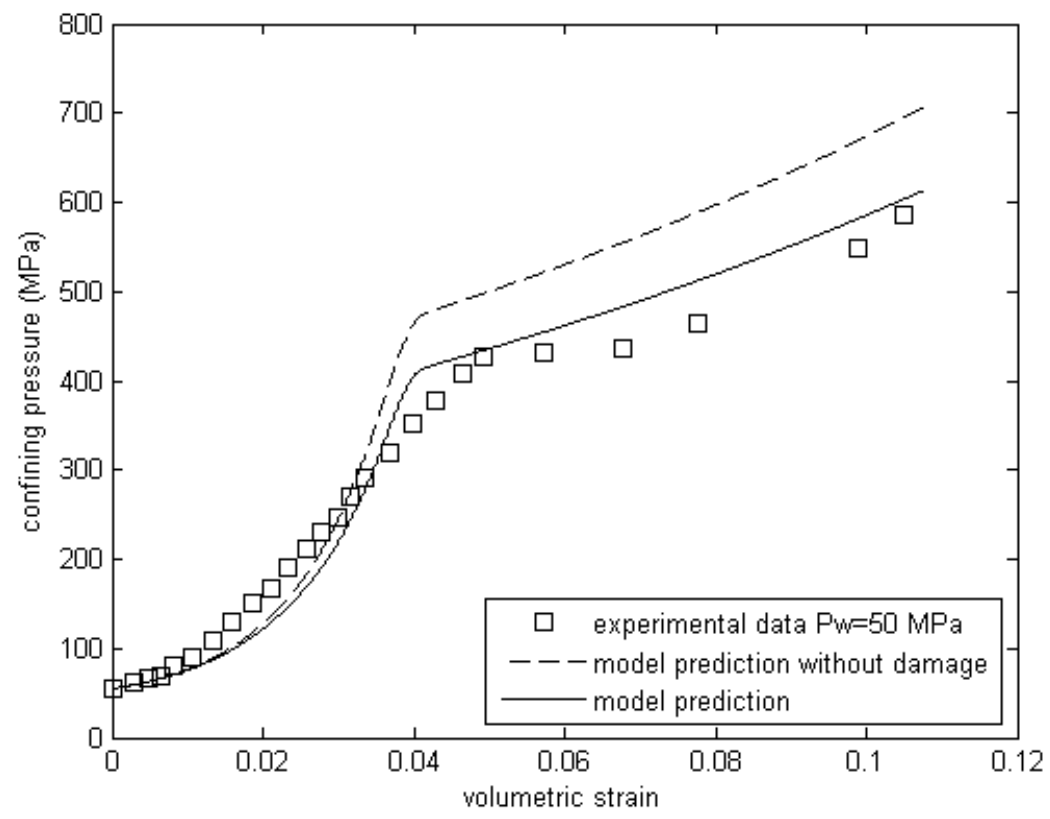

Figure 5 (b)

\section{Figure 5: Comparison between the model prediction and the experimental data for Berea} sandstone under the hydrostatic test: (a) pore water pressure $p_{w}=10 \mathrm{MPa}$, (b) pore water

$$
\text { pressure } p_{w}=50 \mathrm{MPa} \text {. }
$$

Figure 5 shows that the model predictions match the experimental results well for Berea sandstone with different pore water pressures. The proposed model captures the general trend of the test data with acceptable accuracy: initial steep response followed by flat response in the confining pressure-strain plots. Comparison between the model simulation results with and without damage indicates that better results can be achieved in isotropic tests when damage is taken into account.

\subsection{Drained Triaxial Compression Test on Boise Sandstone}

Baud et al. (2000) conducted triaxial compressive experiments on different types of rock materials (Boise, Berea, Darley Dale, and Gosford sandstones). Boise sandstone with a porosity of $35 \%$ is simulated using the present model. The rock sample with a diameter of 
$1 \quad 18.4 \mathrm{~mm}$ and a length of $38.1 \mathrm{~mm}$, was fully saturated. Experiments were conducted at a

2 fixed pore water pressure of $10 \mathrm{MPa}$ under the drained condition. The confining pressures

3 range from $5 \mathrm{MPa}$ to $300 \mathrm{MPa}, \bar{p}_{c}^{\prime}=450 \mathrm{MPa}$, and a fixed normal axial strain rate of

$4 \quad 1.3 \times 10^{-5}$ was applied. The normal axial strain was compared against the average shear

5 stress and pore change (or volumetric strain) using the model prediction and experimental

6 results (see Figures 6 and 7). The damage evolution process of Boise sandstone under various

7 confining pressures is shown in Figure 8. The essential constitutive model parameters are

8 listed in Table 1.

Table 1: Parameters for the model prediction in Boise sandstone

\begin{tabular}{ccccccccc}
\hline $\begin{array}{c}\text { Plastic model } \\
\text { parameters }\end{array}$ & $e$ & $\lambda$ & $\kappa$ & $M_{c s}$ & $N$ & $R$ & $k$ & $k_{m}$ \\
\hline & 0.5385 & 0.10 & 0.033 & 1.7 & 1.80 & 2.35 & 1 & 16 \\
\hline $\begin{array}{c}\text { Damage model } \\
\text { parameters }\end{array}$ & $m$ & $k_{Y}$ & $m_{Y}$ & $Y_{d 0}$ & & & & \\
\hline & 10 & 0.005 & 25 & 0.001 & & & & \\
\hline
\end{tabular}




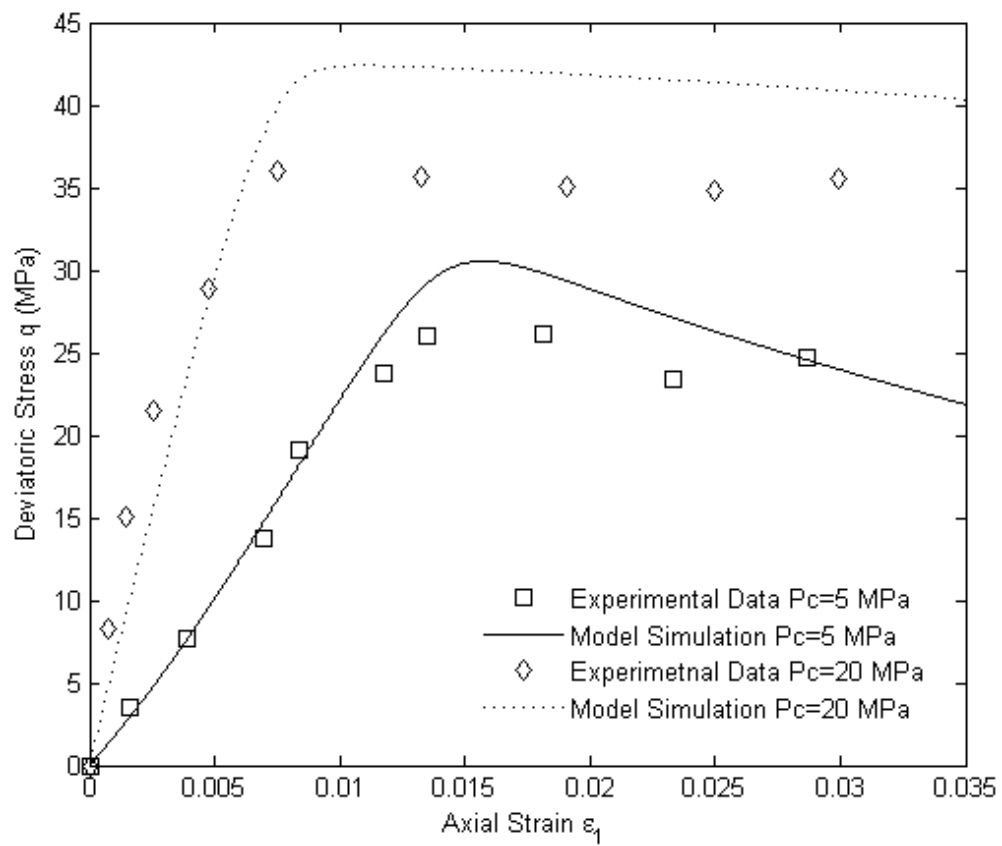

Figure $6(\mathbf{a})$

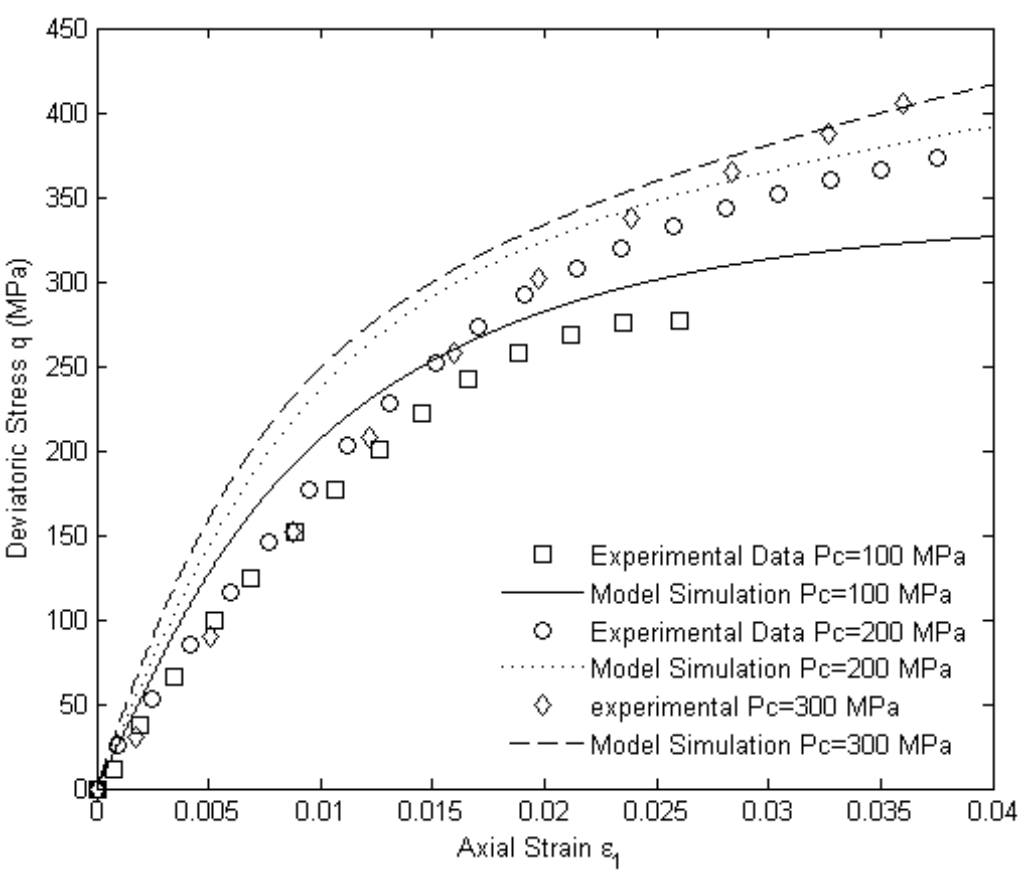

Figure 6 (b)

5 Figure 6: Deviatoric stress comparison of the model prediction and experimental data of Boise sandstone under different confining pressures: (a) $p_{c}=5-20 \mathrm{MPa}$ and (b) $p_{c}=100-300 \mathrm{MPa}$. 

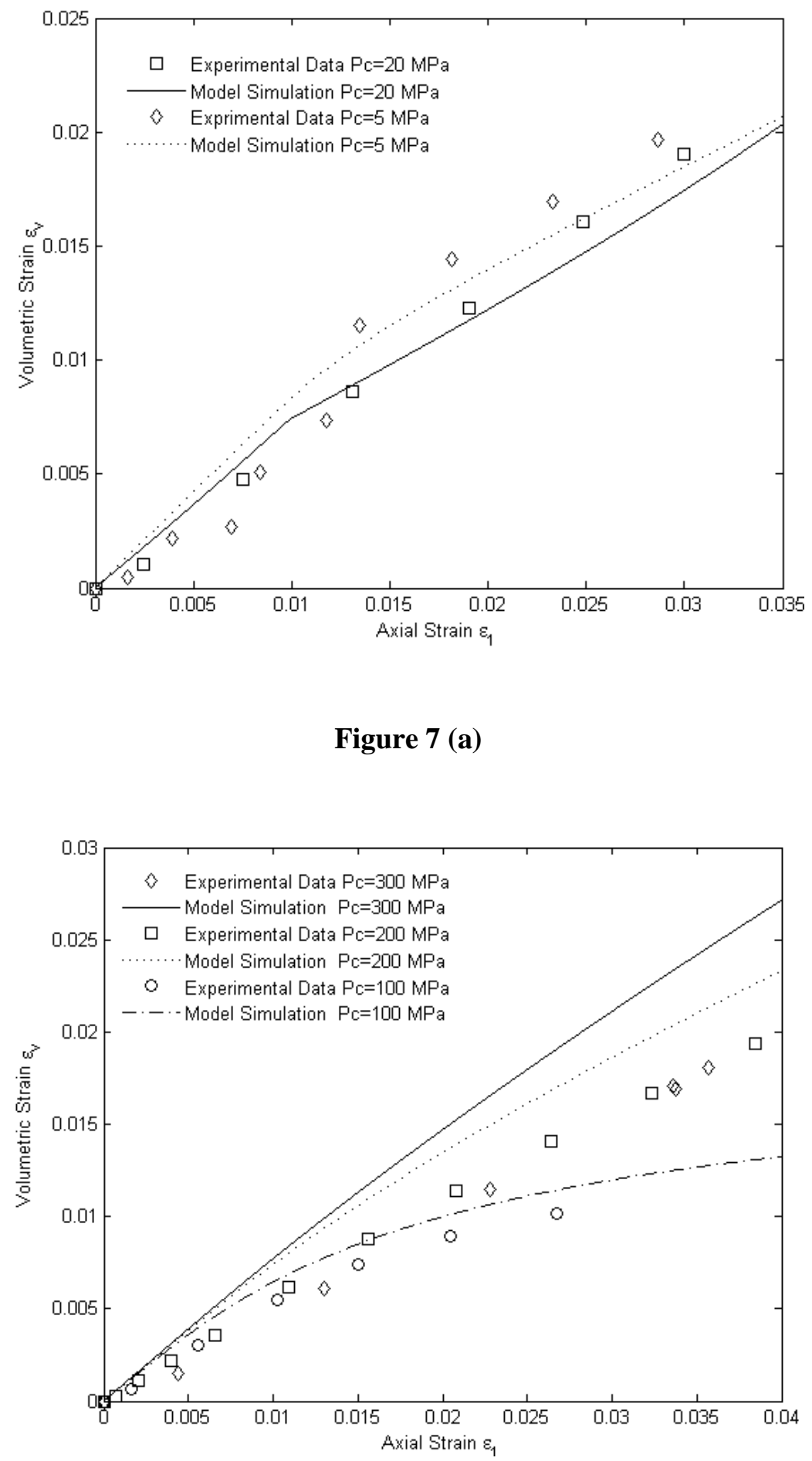

Figure 7 (b)

5

Figure 7: Volumetric change comparison of the model prediction and experimental data of

Boise sandstone under different confining pressures: (a) $p_{c}=5-20 \mathrm{MPa}$ and (b)

$$
p_{c}=100-300 \mathrm{MPa} \text {. }
$$


1 Figures 6 and 7 show that the response of fully saturated Boise sandstone under different

2 confining pressures is reasonably captured by the proposed model. At a lower confining

3 pressure ( $5 M P a)$, the shear stress increases up to the peak value in the $q-\varepsilon_{1}$ plane, and it then

4 decreases to the residual state due to softening. At higher confining pressures $(100 \sim 300 M P a)$,

5 the shear hardening has been captured. A brittle-ductile transition state also has been captured

6 by this model where an intermediate confining pressure is applied (20MPa). Note that only

7 volumetric contraction has been observed for all rock samples (Figure 7), which is simulated

8 with reasonable accuracy. Figure 8 shows that the damage increases dramatically with

9 loading for the test under a low confining pressure; it reaches its maximum at a pressure of 5

$10 \mathrm{MPa}$. As the confining pressure increases (100 300MPa), the damage develops very slowly,

11 as an example, the maximum damage level reaches approximately 5\% under a pressure of

$12300 \mathrm{MPa}$. Also, from low to high confining pressure, the transition from strain softening to

13 strain hardening as well as the brittle-ductile transformation in Boise sandstone are well

14 simulated.

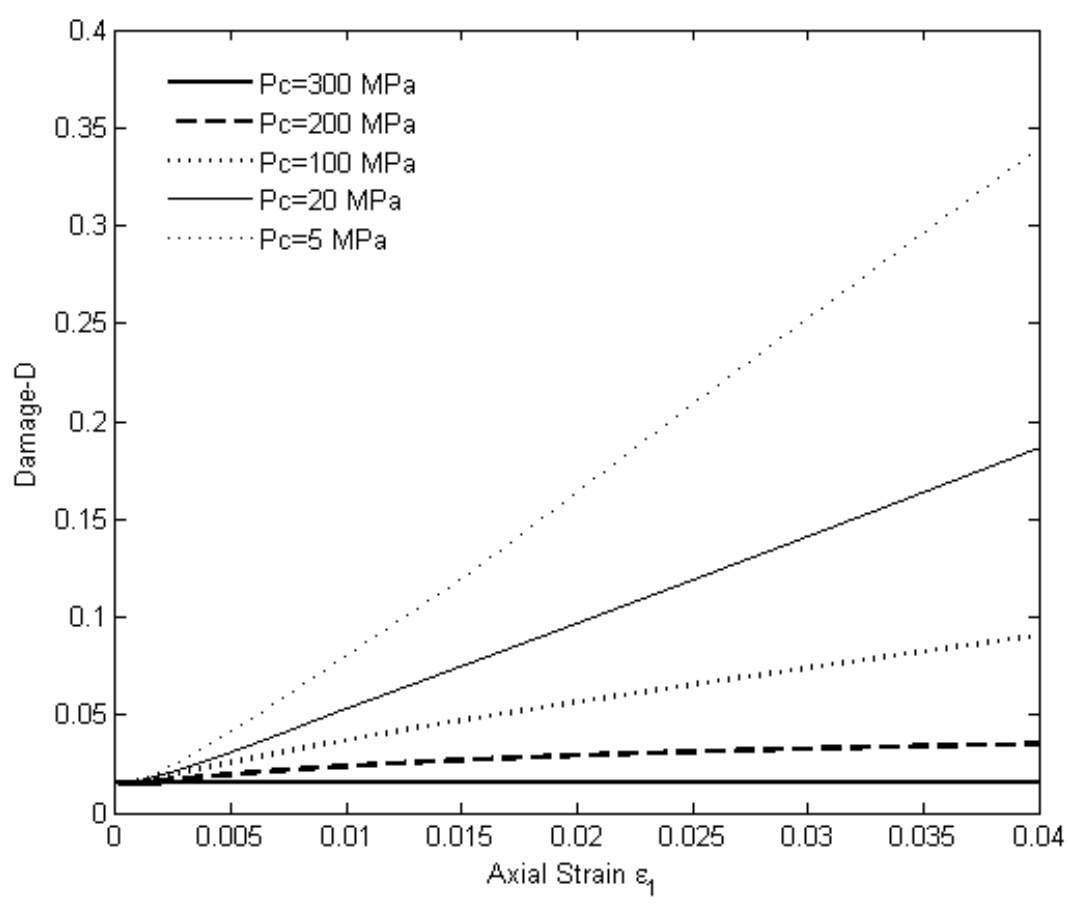


4 Diatomaceous mud rock was made into a cylindrical shape with a diameter of $50 \mathrm{~mm}$ and a

\begin{tabular}{lcccccccc}
\hline $\begin{array}{c}\text { Plastic model } \\
\text { parameters }\end{array}$ & $e$ & $\lambda$ & $\kappa$ & $M_{c s}$ & $N$ & $R$ & $k$ & $k_{m}$ \\
\hline & 2.38 & 0.5625 & 0.035 & 1.75 & 2 & 2 & 4 & 2 \\
\hline Damage model & $m$ & $k_{Y}$ & $m_{Y}$ & $Y_{d 0}$ & & & & \\
parameters & & & & & & & & \\
\hline & 10 & 0.005 & 25 & 0.001 & & & & \\
\hline
\end{tabular}

11 For the sake of simplicity, the compressibility for the fluid and solid grains is ignored for all 12 mud rocks in this study.

the damage strain energy release rate).

\subsection{Undrained Triaxial Compression Test on Diatomaceous Mud Rock}

height of $100 \mathrm{~mm}$, and all samples were fully saturated and tested under the undrained condition. This type of rock belongs to the family of soft/weak rock with high porosity (void ratio $e=2.38$ ), but it is stiff. The maximum historic compressive stress is $\bar{p}_{c}^{\prime}=3500 \mathrm{KPa}$, more details of the material features can be found in Liao et al. (2003). The material parameters applied in this study are listed in Table 2.

Table 2: Material parameters for diatomaceous mud rock 


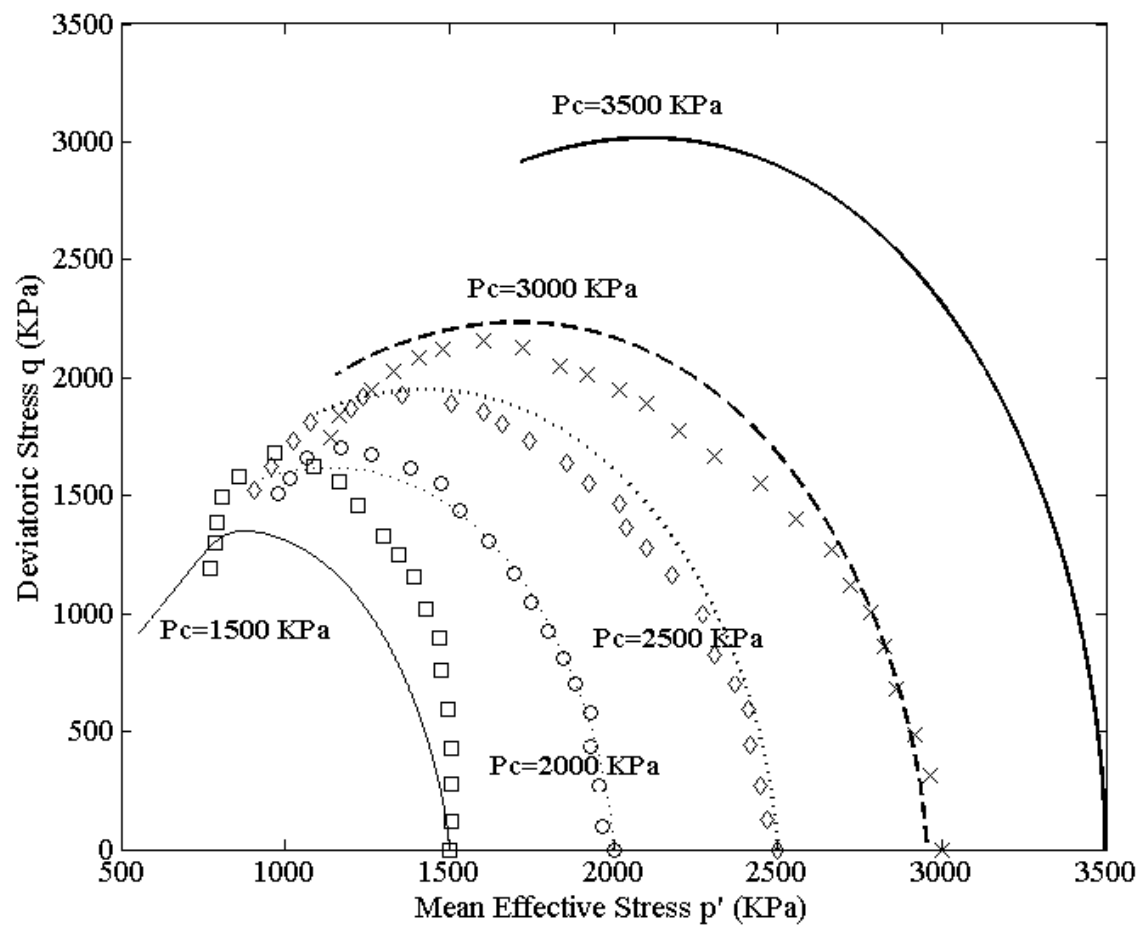

Figure 9: The model simulation and experimental data for diatomaceous mud rock: mean effective stress-deviatoric stress in undrained triaxial tests under different confining pressures.

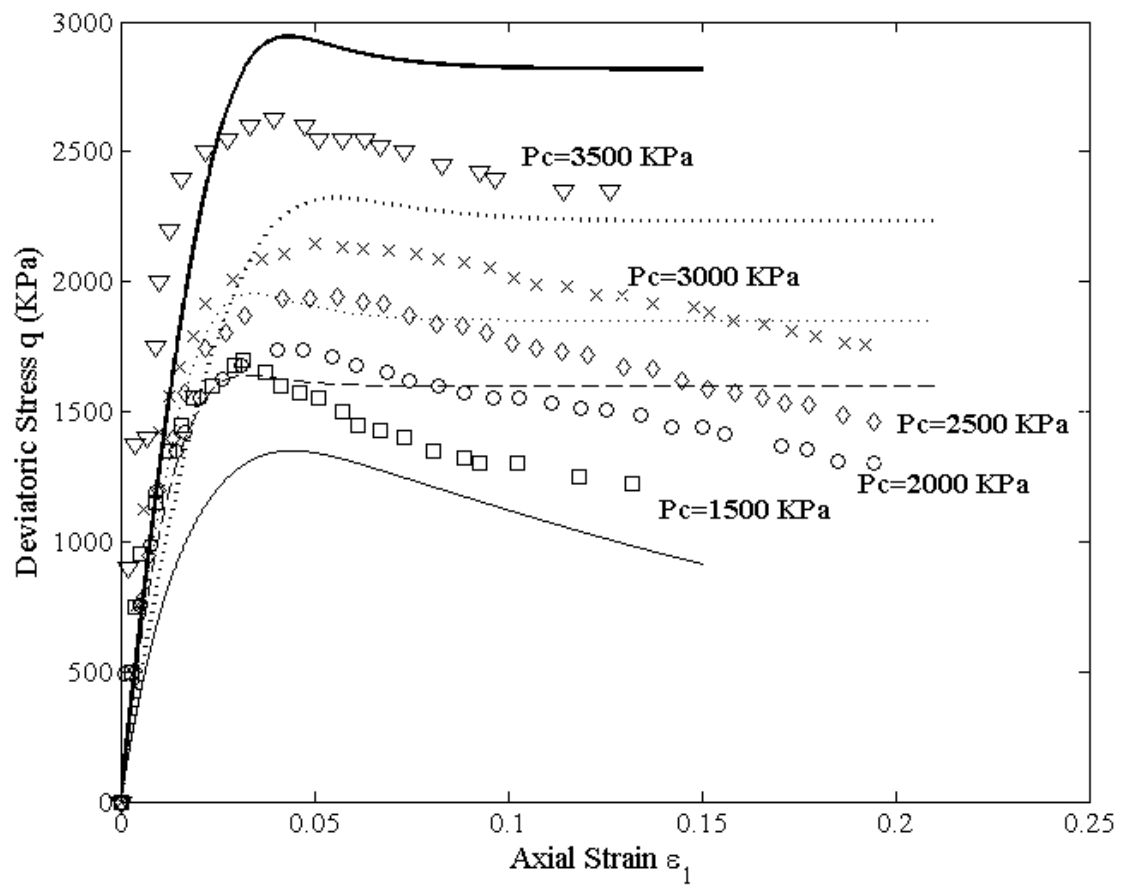

Figure 10: The model simulation and experimental data for diatomaceous mud rock: deviatoric stress-axial strain in undrained triaxial tests under different confining pressures. 


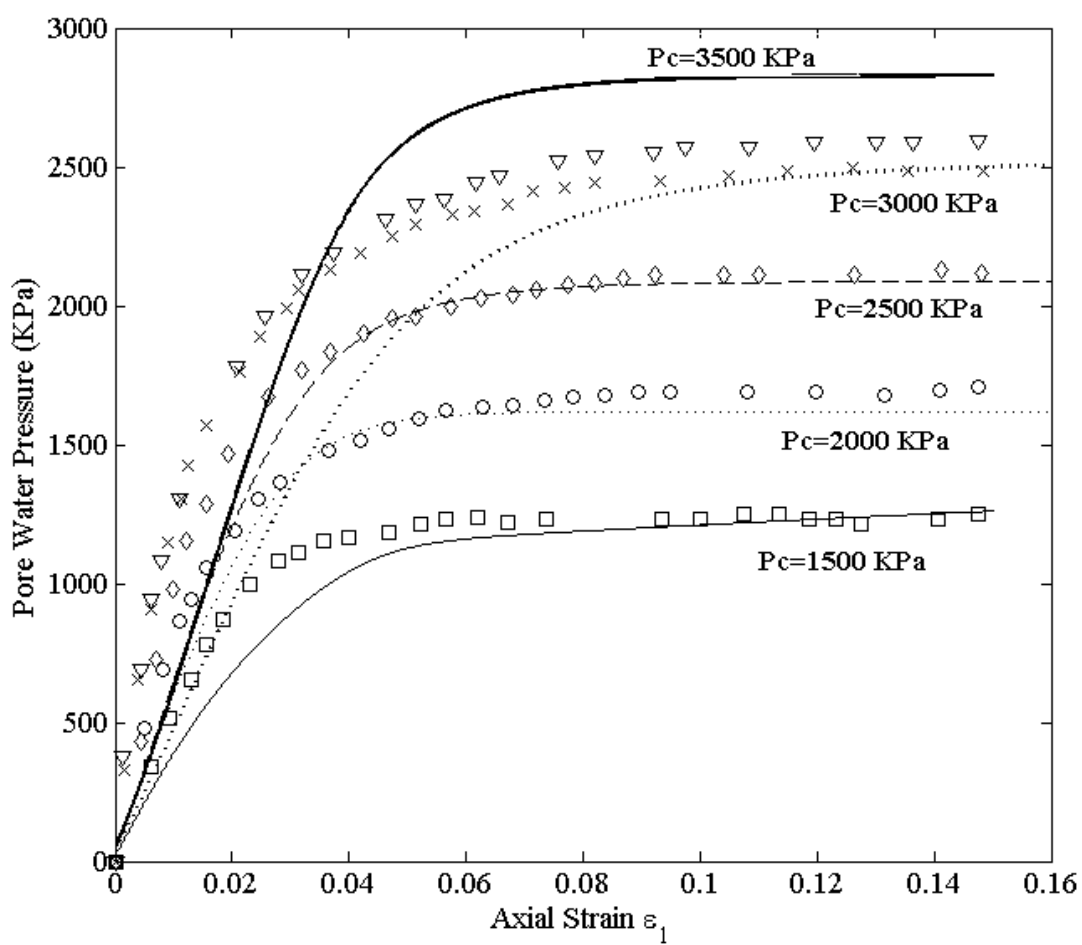

2 Figure 11: The model simulation and experimental data for diatomaceous mud rock: pore water pressure development in undrained triaxial tests under different confining pressures.

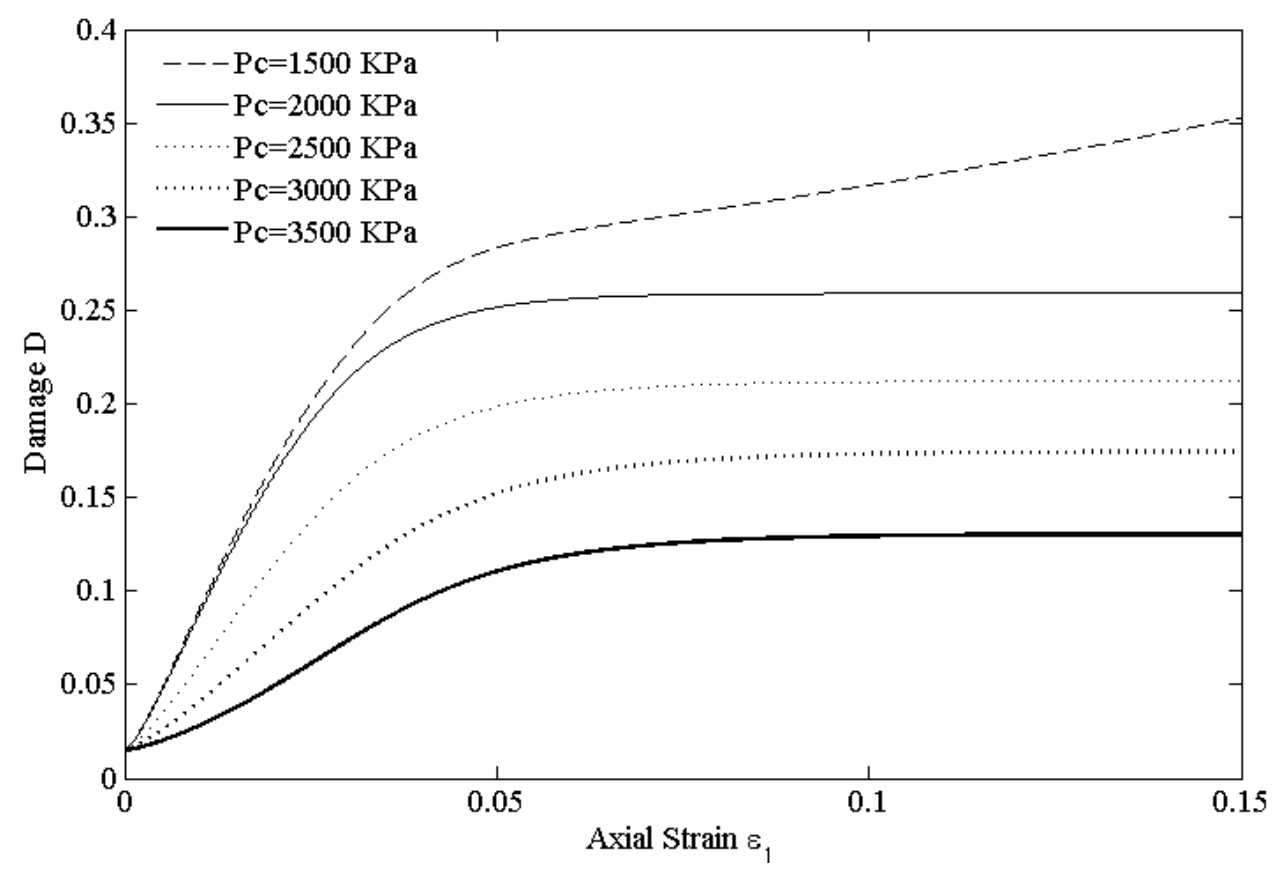

Figure 12: Damage evolution for diatomaceous mud rock under undrained triaxial tests under different confining pressures. 
1 The model predictions and experimental data are used to compare the deviatoric stress

2 against the effective mean stress in Figure 9 and the deviatoric stress-shear strain in Figure

310 , and the excess pore water pressure is compared against the axial strain in Figure 11. Good

4 agreement between the model simulation and experimental results highlights that the

5 proposed model is valid for fractured porous media under undrained conditions. The

6 proposed model captures the effective stress paths, the initial hardening until a peak value

7 followed by softening in the stress-strain plots and the responses of excess pore water

8 pressure observed in all cases with acceptable accuracy. Figure 12 shows the model

9 predictions for the damage evolution against the axial strain, which demonstrates that rock

10 samples under higher confining pressure achieve lower values in damage under undrained

11 condition.

\section{Conclusions}

13 An elastoplastic damage model is presented to describe the stress-strain relationship of 14 fractured porous media subject to various compressive stresses. Bounding surface plasticity is applied to formulate the elasto-plastic equations; a non-associated flow rule is developed, which is more fit with the observation of rock behaviour. The damage model is formulated in the framework of thermodynamics, more rigorous treatment of damage evolution laws is proposed. For the sake of simplicity, isotropic damage assumption is adopted in this paper. The constitutive parameters can be easily obtained from isotropic and triaxial compressive experiments.

21 The proposed model is implemented by comparing the results of model predictions and experimental data from literature. The brittle, brittle-ductile transition, plastic damage hardening/softening effects and post failure behaviours of rock materials under various 
loading conditions are simulated to good accuracy. The confining pressure effects on plastic damage evolution and the coupling effects between plastic hardening/softening and damage evolution are captured. Good performance of the proposed model demonstrates that it is suited to engineering application with a wide range of compressive pressure.

\section{Acknowledgements}

This work is supported by National Science Foundation of China (NSFC, NO. 51508416), Science Foundation of Wenzhou (SFW, NO. S20140011). The financial support is gratefully acknowledged. The collaboration between Wenzhou University (China), Tianjin University (China) and UNSW Australia is also acknowledged.

\section{Reference}

Arslan, G., 2007. Sensitivity study of the Drucker-Prager modeling parameters in the prediction of the nonlinear response of reinforced concrete structures. Mater. Des. 28, 2596-2603.

Baud, P., Zhu, W., Wong, T.F., 2000. Failure mode and weakening effect of water on sandstone. J. Geophys. Res. B: Solid Earth 105, 16371-16389.

Cuss, R.J., Rutter, E.H., Holloway, R.F., 2003. The application of critical state soil mechanics to the mechanical behaviour of porous sandstones. Int. J. Rock Mech. Min. Sci. 40, 847-862.

de Borst, R., 2002. Fracture in quasi-brittle materials: a review of continuum damage-based approaches. Eng. Fract. Mech. 69, 95-112.

Dolarevic, S., Ibrahimbegovic, A., 2007. A modified three-surface elasto-plastic cap model and its numerical implementation. Comput. Struct. 85, 419-430.

Guo, P.J., Wan, R.G., 1998. Modelling the cyclic behaviour of brittle materials using a bounding surface plasticity-damage model. Int. J. Rock Mech. Min. Sci. 35, 437-438.

Kachanov, L., 1980. Crack and damage growth in creep - A combined approach. Int. J. Fract. 16, R179-R181.

Khalili, N., Habte, M.A., Valliappan, S., 2005. A bounding surface plasticity model for cyclic loading of granular soils. Int. J. Numer. Methods Eng. 63, 1939-1960.

Lemaitre, J., 1984. How to use damage mechanics. Nucl. Eng. Des. 80, 233-245.

Lemaitre, J., 1985. A Continuous Damage Mechanics Model for Ductile Fracture. J. Eng. Mater. Techn. 107, 83-89.

Lemaitre, J., Chaboche, J.L., 1975. A nonlinear model of creep-fatigue damage cumulation and interaction, in: Hult, J. (Ed.), Proc.IUTAM Symp. of Mechanics of visco-elastic media and bodies. Springer-Verlag, Gothenburg, Berlin, pp. 291-301.

Lemaitre, J., Chaboche, J.L., 1978. Aspect phénoménologie de la rupture par endommagement. J. Mécan. Appl. 2, 317-365.

Liao, H.J., Su, L.J., Pu, W.C., Yin, J.H., 2003. Test and numerical analysis of the constitutive relation of a diatomaceous soft rock. Mar. Georesourc. Geotechn. 21, 183-200. 
Ma, J., Zhao, G., Khalili, N., 2016. A fully coupled flow deformation model for elasto-plastic damage analysis in saturated fractured porous media. Int. J. Plast. 76, 29-50.

Ofoegbu, G.I., Curran, J.H., 1992. Deformability of intact rock. Int. J. Rock Mech. Min. Sci. Geomech. Abstr. 29, 35-48.

Shah, K.R., 1997. An elasto-plastic constitutive model for brittle-ductile transition in porous rocks. Int. J. Rock Mech. Min. Sci. Geomech. Abstr. 34, 367.

Shao, J.F., Jia, Y., Kondo, D., Chiarelli, A.S., 2006. A coupled elastoplastic damage model for semibrittle materials and extension to unsaturated conditions. Mech. Mater. 38, 218-232.

Shojaei, A., Dahi Taleghani, A., Li, G., 2014. A continuum damage failure model for hydraulic fracturing of porous rocks. Int. J. Plast. 59, 199-212.

Sinha, T., Curtis, J.S., Hancock, B.C., Wassgren, C., 2010. A study on the sensitivity of DruckerPrager Cap model parameters during the decompression phase of powder compaction simulations. Powd. Techn. 198, 315-324.

Valliappan, S., Murti, V., Wohua, Z., 1990. Finite element analysis of anisotropic damage mechanics problems. Eng. Fract. Mech. 35, 1061-1071.

Wong, T.-F., Christian, D., Zhu, W., 1997. The transition from brittle faulting to cataclastic flow in porous sandston: Mechanical deformation. J. Geophys. Res. 102, 3009-3025.

Yazdchi, M., Valliappan, S., Zhang, W., 1996. A continuum model for dynamic damage evolution of anisotropic brittle materials. Int. J. Numer. Methods Eng. 39, 1555-1583.

Yuan, S.C., Harrison, J.P., 2006. A review of the state of the art in modelling progressive mechanical breakdown and associated fluid flow in intact heterogeneous rocks. Int. J. Rock Mech. Min. Sci. 43, 1001-1022.

Zhang, J., Wong, T.F., Davis, D.M., 1990a. Micromechanics of pressure-induced grain crushing in porouse rocks. J.Geophys. Res. 95: 341-352.

Zhang, J., Wong, T.F., Yanagidani, T., Davis, D.M., 1990b. Pressure-induced microcracking and grain crushing in berea and boise sandstones: acoustic emission and quantitative microscopy measurements. Mech. Mater. 9, 1-15.

Zhou, H., Bian, H.B., Jia, Y., Shao, J.F., 2013. Elastoplastic damage modeling the mechanical behavior of rock-like materials considering confining pressure dependency. Mech. Res. Commun. 53, 1-8. 